\title{
How Monitoring Influences Trust: A Tale of Two Faces
}

\author{
Maurice E. Schweitzer \\ Wharton School, University of Pennsylvania \\ Philadelphia, PA 19104 \\ E-mail: Schweitzer@wharton.upenn.edu
}

Teck H. Ho

Haas School of Business

University of California at Berkeley

Berkeley, CA 94720

E-mail: hoteck@haas.berkeley.edu

\author{
Xing Zhang \\ NUS Business School \\ National University of Singapore \\ Email: zhangxingis@gmail.com
}

October 6, 2014 


\title{
How Monitoring Influences Trust: A Tale of Two Faces
}

\begin{abstract}
Organizations operate more effectively when managers trust their employees. In many cases, however, managers and their employees have divergent interests. One common managerial approach to address the problem of misaligned incentives involves monitoring employee behavior. In this paper, we investigate how monitoring changes the behavior of both those who are monitored and those who monitor others. Across three experiments, we paired participants in repeated trust games with different monitoring conditions. In each iteration of the repeated trust game, a trustor must decide how much money to pass to a trustee. The money passed is either tripled or quadrupled; the trustee must then decide how much money to return to the trustor. In each of three studies, we included conditions with anticipated monitoring. When trustees could anticipate monitoring, they engaged in opportunistic behavior; they returned more money than they received when they anticipated that they would be monitored, but either returned a small amount or nothing at all when they anticipated that they would not be monitored. Trustors, however, failed to appreciate how strategically their counterparts would act and continued to pass money to their counterparts even when they were unable to monitor them. Across three studies, we find that trustors systematically over-relied on the compliant behavior they observed during monitoring. We discuss managerial implications of these results for designing and using monitoring systems.
\end{abstract}




\section{INTRODUCTION}

Trust plays a central role in individual relationships and within organizations (Lewicki, Tomlinson and Gillespie 2007). Trust promotes cooperation (Pillutla, Malhotra and Murnighan 2003) and broadly impacts workplace behavior (Dirks and Ferrin 2001; Kim, Dirks, Cooper and Ferrin 2006). Managers who develop trusting relationships with their employees are more effective.

Promoting trust and trustworthy behavior, however, represents a constant managerial challenge (Ho and Weigelt 2005; Kim, Ferrin, Cooper, and Dirks 2004; Kim, Dirks, Cooper, and Ferrin 2006; Kramer and Lewicki 2010). Managers need to trust their employees to use organizational resources to accomplish workplace goals, but their trust is often misplaced. A typical organization loses about $5 \%$ of its revenues from occupational fraud, actions that include employee theft and inflated expense reporting (Association of Certified Fraud Examiners 2012).

One tool that managers use to contend with this challenge of promoting compliant behavior is employee monitoring. In an American Management Association survey, 66\% of managers reported that they monitor the internet connections of their employees. Almost half of the companies surveyed reported that they use video monitoring, and nearly half (43\%) monitor e-mail use and use other detailed tracking methods, such as tracking the keystrokes of their employees (45\%). Monitoring systems, however, are expensive and their effectiveness is limited by a scare resource: managerial attention. As a result, managers can observe only a limited sample of employee behavior. For example, supervisors in most call centers listen to only a small fraction of the calls handled by the operators they oversee.

Monitoring can also change perceptions and hence subsequent behavior. In this paper, we investigate employee monitoring, a theoretically important and practically relevant, but understudied managerial tool. We examine how monitoring influences trust and trustworthy behavior in a laboratory experiment with participants motivated by financial incentives. We build on prior work to define trust as the willingness to accept vulnerability based upon positive expectations of another person (Mayer, Davis and Schoorman 1995), and we study how trust between paired participants changes over time (Kim, Ferrin, Cooper, and Dirks 2004; Schweitzer, Hershey, and Bradlow 2006).

We study how people change their compliant behavior as a function of being monitored, and more importantly, how people change the trust they place in others as a function of what they observe. Specifically, we analyze behavior in repeated trust games with varying monitoring conditions. In each iteration of the repeated trust game, a trustor must decide whether or not to trust a trustee by passing the latter some money. The money passed is either tripled or quadrupled; the trustee must then decide whether or not to return more than what they received to the trustor. In this repeated trust game, we found that trustees and trustors responded to monitoring in an asymmetric manner: trustees strategically responded to monitoring, returning more money than they received when they anticipated that they would be monitored, but returning the same 
or less than they received when they anticipated that they would not be monitored. Trustors, however, failed to anticipate how opportunistic their counterparts would behave when they were not monitored. Our analyses reveal that trustors relied too heavily on the information they were able to observe. By extrapolating from a biased set of observations, trustors mispredicted the trustworthiness of their counterparts when they were not monitored.

The remainder of this paper proceeds as follows: in Section 2, we review the literature on trust and monitoring; in Section 3, we develop our hypotheses; in Section 4, we establish the main empirical regularities (Study 1) and discuss alternative explanations; in Sections 5 and 6, we present two studies (Studies 2 and 3) that test alternative explanations and explore underlying mechanisms. In Section 6, we report additional analyses based on the attitudinal data we collected from the experiments; these analyses offer additional insight into the underlying mechanism. In Section 7, we highlight managerial implications of our results, discuss limitations, and identify directions for future research.

\section{LITERATURE REVIEW}

\section{Experimental Studies of Trust}

An emerging body of research has used experimental methods to deepen our understanding of trust (e.g., Malhotra 2004; Pillutla, Malhotra and Murnighan 2003). This stream of research investigates how incentives (Lewicki, Tomlinson, and Gillespie 2006), formal contracts (Malhotra and Murnighan 2002), reciprocity (Pillutla, Malhotra and Murnighan 2003), implicit beliefs (Haselhuhn, Schweitzer and Wood 2010), and emotions (Dunn and Schweitzer 2005; Lount 2010) influence trust. For example, Malhotra and Murnighan (2002) found that the use of contracts impeded trust development. When individuals behave in a trustworthy way after agreeing to a contract, observers attribute their trustworthy behavior to the contract. That is, rather than making a personal attribution for the trustworthy behavior, observers made situational attributions and assume that individuals had behaved in a trustworthy way because of the contract.

Much of the prior work studying trust has used a modified version of Berg, Dickhaut, and McCabe’s (1995) trust game. In this game, an individual (the trustor) starts with a pot of money (e.g., \$20) and can either keep the money for herself or pass a fraction of the money to her partner. If she passes $\$ x$ to her partner (the trustee), the amount of money grows (e.g., triples to $\$ 3 x$ ), and the trustee must then decide how to split the resulting sum of money between the trustor and himself (e.g., by splitting it evenly, $\$ 1.5 x$ each, or by keeping the entire $\$ 3 x$ to himself). In a trust game with an initial endowment of $\$ 20$ that tripled, Berg et al. (1995) found that trustors passed an average of $\$ 5.16$ (out of their initial sum of $\$ 20$ ), and trustees returned an average of $\$ 4.66$ to trustors. In this case, trust did not pay. Trustors who trusted their counterparts and passed money were worse off, on average, than those who did not. 
In our study, participants play a multi-round trust game; participants play a series of trust games with the same partner. Repeated trust games have been used to study trust building (Pillutla, Malhotra, and Murnighan 2003; Ho and Weigelt, 2005) and trust repair (Schweitzer, Hershey, and Bradlow 2006; Kim, Dirks, Cooper, and Ferrin 2006; Lount, Zhong, Sivanathan and Murnighan 2008). In our studies, we use a repeated trust game to study the influence of monitoring. Trustors in our studies only receive partial feedback about the trustees' behavior. In monitored rounds, trustors learn how much their trustee counterparts returned in that particular round, whereas in non-monitored rounds, trustors do not learn information about the trustees' decision in that round, until the very end of the experiment. This design enables us to explore the influence of monitoring on trust and trustworthy behavior.

\section{Monitoring and Trust}

Surveillance and monitoring systems pervade the workplace (Aiello 1993), and these systems may influence relationships between employers and employees (Kramer 1999). For example, monitoring systems may harm intrinsic motivation and communicate negative expectations (Cialdini 1996; Enzle and Anderson 1993). By monitoring employees, managers may signal that they expect unmonitored employees to shirk (Frey 1993). In some cases, however, monitoring can promote perception of fairness (Niehoff and Moorman 1993) and increase trustworthy behavior (Schweitzer and Ho 2005).

Monitoring systems can also influence the attributions observers make. Strickland (1958) found that frequent monitoring caused observers to become more likely to make external attributions for the compliant behavior they observed. That is, rather than making a personal attribution for compliant behavior under monitoring, observers may attribute compliant behavior to the monitoring system. Strickland (1958) found that monitoring eroded trust and that those in a position to monitor others demanded even more frequent monitoring. In related work, Kruglanski (1970) found that individuals were far more likely to make personal attributions for trustworthy behavior when they could rule-out external motivations.

In our investigation, Strickland's (1958) findings suggest that if trustors attribute the compliant behavior they observe to the monitoring system, they should be skeptical of the trustee's trustworthiness. As a result, when the trustor cannot monitor the trustee, the trustor should not trust and would not pass money. Other research, however, suggests that people rely heavily on initial interactions as they develop beliefs about other people's character traits (Rotter 1971, 1980). After observing compliant behavior, a trustor may assume that the trustee is compliant and trustworthy. As a result, when the trustor cannot monitor the trustee, the trustor may remain trusting and misplace their trust. We test these conflicting theories in our experiments. 


\section{HYPOTHESES}

We develop two sets of hypotheses. The first set of hypotheses considers how monitoring schemes influence trustee behavior. Within the trust game, we distinguish between two types of trustee behavior: compliant and non-compliant behavior; trustees can exhibit compliant behavior by returning more money than they received, or they may exhibit non-compliant behavior by returning less money than they received. Note that compliant behavior can occur for two separate reasons. Trustees may exhibit compliant behavior either because they are intrinsically trustworthy or because they are keen to manage impressions. Trustees may want their counterpart to believe that they are trustworthy and to continue to pass them money. In anticipated monitoring conditions, both motivations will promote compliance, and we expect trustees to be more likely to return money in the anticipated monitored than non-monitored rounds. Indeed the difference in the incidence of compliant behavior between the anticipated monitored and anticipated non-monitored rounds enables us to assess strategic behavior. In unanticipated monitoring conditions, trustees do not know before they make a decision whether or not their behaviors will be monitored. Hence we do not expect to see a difference in compliant behavior between monitored and non-monitored rounds.

The second set of hypotheses considers how monitoring influences the decision to trust others. These hypotheses focus on how monitoring changes trustor behavior both when trustors are able to and when they are unable to monitor their counterparts. Trustors' willingness to trust is measured by whether or not they pass a strictly positive sum of money to their counterparts.

In developing our hypotheses, we consider two dimensions of monitoring schemes: 1) frequency and 2) anticipation. The frequency of monitoring reflects how often trustees will be monitored. It establishes trustees' prior expectation of being monitored. The anticipation of monitoring reflects whether or not trustees know in advance whether or not they will be monitored in a specific round. That is, anticipation removes trustees' strategic uncertainty of being monitored and allows them to behave opportunistically in monitored and unmonitored rounds. We examine anticipation in this paper because many monitoring schemes let employees know in advance when they will be monitored (e.g., announced visits or advanced warning of monitoring). Other monitoring schemes do not afford trustees with advance notice (unanticipated monitoring). Our paper attempts to determine the benefits and costs of anticipated monitoring.

\section{Trustee Behavior}

In each round, trustees face the decision to act in one of two ways: act in a compliant way and return more money than they receive or act in a noncompliant way and return less money than they receive. The rewards for compliant behavior are greatest when compliant behavior is observable. Although trustees can reap short-term gains by returning less money in monitored rounds, trustors may punish non-compliant 
behavior by not passing money in future rounds. As a consequence, we expect compliant behavior to be the greatest in anticipated monitored rounds and the least in anticipated non-monitored rounds.

A substantial literature suggests that monitoring is likely to change how people behave within organizations. Across many social settings, people work hard to create positive impressions (Leary 1996), and individuals pay closer attention to how they behave when others can observe them than when others cannot observe them (Goffman 1959). People also strategically control the information they reveal and the emotions they express to influence others (Goffman 1959; Andrade and Ho, 2007; Andrade and Ho 2009). Frequently, people work to present themselves in positive ways to get others to like them (Schlenker and Leary 1982). Taken together, we expect that when trustees anticipated monitoring, they will behave differently in monitored rounds from how they behave in non-monitored rounds.

Hypothesis 1: Trustees will exhibit compliant behavior more frequently in anticipated monitored rounds than in anticipated non-monitored rounds.

Trustors will cease to pass money if they observe trustees' non-compliant behaviors (Ho and Weigelt 2005; Lewicki, Tomlinson, and Gillespie 2006). As a result, frequency of monitoring increases the expected cost of engaging in non-compliant behaviors. Hence, we expect frequency of monitoring to increase the incidence of compliant behavior.

Hypothesis 2: Frequency of monitoring increases compliant behavior.

\section{Trustor Behavior}

Trustees are likely to be particularly compliant when they anticipate monitoring. However, when trustees anticipate no monitoring, they are more likely to act opportunistically. If trustors rationally anticipate this, trustors should not pass money to trustees in anticipated non-monitored rounds. In this paper, we explore the thesis that trustors fail to appreciate how strategically trustees will behave. Instead of engaging in perspective taking, trustors may focus on the actual behavior they observe (Lewicki, Tomlinson, and Gillespie 2006). When trustors observe trustees' compliant behavior in monitored rounds, trustors may project (wrongly) that trustees will behave the same way in non-monitored rounds. We postulate that this will be true even when the monitored trustee's behavior may not be representative of the non-monitored trustee's behavior.

Individual behavior reflects both dispositional and situational factors (Epstein \& O’Brien, 1985). The compliant behavior trustors observe may be misattributed as dispositional qualities of the trustees (Rotter 1971, 1980). Perspective taking within social interactions is very difficult (Gilovich, Kruger, and Savitsky 
1999; Malhotra 2004), and we postulate that trustors will over-rely on the biased sample of behavior they observe in monitored rounds. As a result, trustors may make overly-optimistic inferences of trustworthiness and over-predict trustworthy behavior in non-monitored rounds. That is, we hypothesize that trustors will continue to pass money in non-monitored rounds even though they may receive less money in return from the trustees.

Hypothesis 3: Anticipated monitoring will not suppress trusting behavior in non-monitored rounds. We test this hypothesis in two ways:

a. The strong trust inference hypothesis: Trustors believe that trustee behavior is identical in monitored and non-monitored rounds. Hence, there is no difference in trusting behavior between monitored and non-monitored rounds in anticipated monitoring conditions.

b. The weak trust inference hypothesis: Trustors believe that trustee behavior in monitored rounds is representative, at least partially, of trustee behavior in non-monitored rounds. As a result, trusting behavior in non-monitored rounds is significantly greater than zero.

When monitoring is more frequent, trustees are likely to be more compliant. This is true in both anticipated and unanticipated conditions. When monitoring is anticipated, we expect trustees to be compliant in anticipated monitored rounds. When monitoring is unanticipated, we expect trustees to be compliant in any specific round when frequency of monitoring is high because their actions are likely to be monitored in that round. Trust builds over time (Gambetta 1988), and we as a result, expect trustors to be more trusting in the frequent monitoring conditions.

Hypothesis 4: Frequency of monitoring increases trusting behavior.

\section{STUDY 1: MONITORING AND TRUST}

In Study 1, we investigate the relationship between monitoring and trust. In this study, we randomly assigned pairs of participants to different monitoring conditions, and we recorded their behavior in a repeated trust game.

In this game, we randomly assigned participants to assume the role of either the odd or the even player. We used the terms "odd" and "even" instead of "trustor" and "trustee" in the experiments in order to present the roles in neutral terms. Participants played multiple rounds of the game with the same partner in a fixed matching protocol. In each round, the odd player started with an endowment of five points. The odd player decided how much of the five points to keep for himself and how much to pass to his even player counterpart. The even player received a multiple of the amount the odd player passed. In Study 1, the amount 
the odd player passed was quadrupled. For example, if an odd player passed 2 points (and kept 3 points) then the even player received 8 points (i.e., 4 x $2=8$ points). The even player then decided how much to keep for herself and how much to return to the odd player. For example, if the odd player passed 2 points (and the even player received 8 points) and the even player returned 4 points, the odd player would earn 7 points (i.e., $3+4$ ) and the even player would earn 4 points (i.e., 8 - 4). The round ended after the even player made her decision. The same game was repeated multiple times.

\section{Methods}

Participants. We recruited 182 participants from a large Northeastern university in the US to participate in a one-hour laboratory study for a \$10 show up fee and the chance to earn additional money. We recruited participants through an online campus subject pool. Participants completed the study in groups that ranged in size from 6 to 14. The average group size was 8. (If an odd number of participants showed up, one participant was randomly selected, removed from the group, paid $\$ 10$, and dismissed.)

We instructed participants that they would have the opportunity to earn additional money in the experiment. We explained that the total amount that they earned would depend upon the decisions they made, the decisions their partner made, and upon chance. Participants were informed that during the experiment they would earn "points." At the end of the experiment, these points would be summed and converted to cash at the rate: 1 point = 10 cents. We seated each participant at a computer terminal that had partitions on each side. Participants were unable to see the screens of other participants. We randomly and anonymously paired participants with another person in each experimental session. Participants never learned the identity of their partners.

Design. We manipulated the nature of the feedback players received. Although both players made decisions in every round, they did not always learn what their counterparts chose in a particular round. We randomly assigned pairs of participants to one of four treatment conditions from a 2 (frequency: high vs. low) x 2 (anticipation: anticipated vs. unanticipated) factorial design.

We randomly assigned participants to either a high frequency monitoring condition or a low frequency monitoring condition. Within the experiment, we called a monitored round a feedback round. The chance that any one round would be a feedback round was constant within a condition and independent of whether or not the prior round was a feedback round. That is, we used an independent draw to determine whether any given round was a feedback round. In the high frequency condition, there was an $80 \%$ chance that odd players would receive feedback in each round (and learn what their even player counterparts chose for that particular round). In the low frequency monitoring condition, there was a $40 \%$ chance that odd players would receive feedback in each round (and learn what their even player counterparts chose for that particular round). In rounds without monitoring, odd players did not learn what their even player counterparts 
chose for that particular round until the experiment ended. In every round, across all conditions, even players always learned what their odd player counterparts passed to them before they made their decision.

To control for end-game effects, the total number of rounds participants played was randomly determined. Every dyad made 10 rounds of decisions. After the tenth round, participants had an $85 \%$ chance of continuing on to the eleventh round. If there was an eleventh round, there was an $85 \%$ chance of advancing to the twelfth round, and so on. The $85 \%$ chance of advancing to the next round was independent of the number of rounds participants had advanced.

We also randomly assigned participants to either an anticipated monitoring condition or an unanticipated monitoring condition. This condition varied whether or not even players knew before they made their decision if their current round was a feedback round. In the anticipated condition, even players knew before they made their decision whether or not their current round was a feedback round (in which case odd players would learn what they chose). In the unanticipated condition, even players did not know in advance whether or not their current round was a feedback round. Odd players always knew before they made their trusting decision whether or not the upcoming round was a feedback round. They also knew what their even player counterparts knew about the current round.

As a result, each pair of participants belonged to one of the four monitoring conditions from our 2 (frequency) x 2 (anticipation) between-subject design: high frequency-anticipated, low frequency-anticipated, high frequency-unanticipated, and low frequency-unanticipated. Both odd and even players knew details about their own treatment condition, but were unaware of the other three treatment conditions. Within each dyad, participants made decision in monitored and unmonitored rounds. Monitoring is a within-subject factor. We measured both how much the odd player (the trustor) passed and how much the even player (the trustee) returned in each round.

Procedure. After reading the instructions, participants answered a series of comprehension check questions about the nature of the game, the matching protocol, their experimental condition, and the payment scheme. The software program returned participants to the instruction page if they made a mistake answering any of the comprehension check questions. Most participants understood both the game instructions and their experimental condition. However, 13 participants made repeated mistakes answering the comprehension check questions. We dismissed these participants and their partners. In total, we dismissed 11 dyads (in two dyads, both pair members made repeated mistakes answering the comprehension check questions). As a result, a total of 160 participants completed the study.

Each pair of participants played the trust game multiple times. In each round, participants remained in the same role and were matched with the same partner. We summed the points players earned for each round that they played and converted their total points into cash. We paid participants in cash before they left the experiment. 


\section{Results}

We paired the160 participants who completed the study with each other to create 80 dyads. We randomly and independently assigned each dyad to one of four treatment conditions; a total of 42 participants completed the study in the low frequency-anticipated condition, 44 participants completed the study in the high frequency-anticipated condition, 34 completed the study in the low frequency-unanticipated condition, and 40 completed the study in the high frequency-unanticipated condition.

Figure 1a depicts the incidence of the trusting behavior, the amount the trustors passed across the four treatment conditions. Trustors trusted in $83 \%$ of the rounds in the low frequency-anticipated condition, $97 \%$ in the high frequency-anticipated condition, $94 \%$ in the low frequency-unanticipated condition, and $80 \%$ in the high frequency-unanticipated condition. Thus, trustors exhibited a high level of trust in the repeated trust game with a fixed matching protocol.

Figure $1 \mathrm{~b}$ shows trustees' compliant behavior (i.e. when trustees returned more money than they received) across the four treatment conditions. Trustees complied in $61 \%$ of the rounds in the low frequencyanticipated condition, $75 \%$ in the high frequency-anticipated condition, $71 \%$ in the low frequencyunanticipated, and $83 \%$ in the high frequency-unanticipated condition. A striking empirical regularity is that trustees complied significantly less frequently in the non-monitored than monitored rounds in the anticipated conditions. Specifically, across the two anticipated monitoring conditions, trustees complied in $88 \%$ of the anticipated monitored rounds whereas they complied only in 35\% of the anticipated non-monitored rounds (see the left panel in Figure 1b). We next formally test our hypotheses.

Insert Figure 1 about here

Trustee behavior: For each dyad, we have multiple observations in both monitored and nonmonitored rounds. For each trustee, we computed the incidence of compliance across her entire decision history to derive a separate compliance measure for monitored and non-monitored rounds. Our statistical tests were based on a 2 (frequency) x 2 (anticipation) x 2 (monitoring) ANOVA with repeated measures. Monitoring is the within-subject factor. ${ }^{1}$

\footnotetext{
${ }^{1}$ In our design, whether a round would be monitored or not was determined by chance. Because of the randomness, two dyads in the high frequency monitoring conditions did not experience non-monitored rounds. In addition, two trustees did not have a chance to make decision in non-monitored rounds because trustors did not pass any money in these rounds. As a result, we have no observations for these four trustees in non-monitored rounds. These trustees were excluded from testing Hypothesis 1.
} 
Hypothesis 1 states that when monitoring is anticipated, trustees would exhibit more frequent compliant behavior in monitored than non-monitored rounds. As we observed in Figure 1b, the incidence of compliance is significantly higher in anticipated monitored than non-monitored rounds. This difference in compliance is significant in both the low frequency monitoring condition $\left(M_{\text {Monitored }}=93 \%\right.$, $M_{\text {NonMonitored }}=$ $33 \%, F(1,72)=47.86, p<0.001)$ as well as the high frequency monitoring condition $\left(M_{\text {Monitored }}=85 \%\right.$, $\left.M_{\text {NonMonitored }}=39 \%, F(1,72)=37.49, p<0.001\right)$. Thus, Hypothesis 1 is supported.

In addition, the amount trustees returned in monitored rounds was more than double the amount they returned in non-monitored rounds (low frequency monitoring conditions: $M_{\text {Monitored }}=8.13, M_{\text {NonMonitored }}=3.17$, $F(1,72)=54.49, p<0.001$; high frequency monitoring conditions: $M_{\text {Monitored }}=7.94, M_{\text {NonMonitored }}=3.74, F(1$, $72)=47.16, p<0.001)^{2}$. These results suggest that trustees behaved strategically in anticipated monitoring conditions.

We examined the heterogeneity in compliant behavior among trustees. The left panel of Figure 1c plots trustees' incidence of compliant behavior in non-monitored rounds ( $\mathrm{y}$-axis) against monitored rounds ( $\mathrm{x}$ axis). If trustees exhibited the same level of compliance in non-monitored as in monitored rounds, all points should fall along the 45 degree line. Results from 30 out of 42 (71\%) trustees fell below the 45 degree linethese participants behaved more compliantly in monitored than they did in non-monitored rounds. ${ }^{3}$ Results from 9 out of 42 trustees (21\%) fell on the 45 degree line-these participants behaved identically in both monitored and non-monitored rounds; of these 9 trustees, 6 always complied. Surprisingly, 3 trustees were more compliant in non-monitored than monitored rounds. Overall, these results suggest that a large majority of the trustees behaved strategically.

In this study, the amount trustors passed to their trustee counterparts quadrupled. As a result, trustors' decision to trust always pays as long as trustees return at least $25 \%$ of what they receive. For instance, if a trustor passed 1 point, her trustee counterpart would receive 4 points. If the trustee counterpart returned 50\% of what he received, the trustor would earn 2 points, a 100\% rate of return. If the trustee returned 1 point (i.e., $25 \%$ ), the trustor would earn a $0 \%$ rate of return. Hence " $25 \%$ " is the cut-off value of whether or not the decision to trust is profitable. As expected, trustees returned the highest percentage in the anticipated monitored rounds and the lowest percentage in the anticipated non-monitored rounds (in the infrequent monitoring condition: $M_{\text {Monitored }}=46 \%, M_{\text {NonMonitored }}=19 \%, F(1,72)=48.12, p<0.001$; in the frequent monitoring condition: $\left.M_{\text {Monitored }}=45 \%, M_{\text {NonMonitored }}=23 \%, F(1,72)=38.18, p<0.001\right)$. As a result, trustors'

\footnotetext{
${ }^{2}$ Similarly, we calculated the average amount returned for each trustee in both monitored and non-monitored rounds. We used the composite measure as the dependent variable in the ANOVA.

${ }^{3}$ An individual-level proportion test indicates that 19 out of 30 of these strategic trustees were significantly more compliant in non-monitored rounds than in monitored rounds (two-tailed proportion test: $p<0.05$ ).
} 
rates of return were significantly different between the anticipated monitored and non-monitored rounds. In the $80 \%$ anticipated monitoring condition, trustors earned an $80.9 \%$ (95\% CI: [67\%, 95\%]) ${ }^{4}$ rate of return in monitored rounds, but a $-7.9 \%$ (95\% CI: [-45\%, 39\%]) rate of return in the non-monitored rounds. In the $40 \%$ anticipated monitoring condition, trustors earned an 84.8\% (95\% CI: [72\%, 98\%]) rate of return in monitored rounds, but a $-23.9 \%$ (95\% CI: [-60\%, 12\%]) rate of return in non-monitored rounds. Overall, these results suggest that trustors enjoyed a significantly positive return in monitored rounds, but a return that is statistically not different from zero in non-monitored rounds.

Hypothesis 2 states that the frequency of monitoring increases compliant behavior. We collapsed the within-subject factor and focused on the between subject factors. A 2 (frequency) x 2 (anticipation) ANOVA reveals a significant main effect for frequency: when the monitoring frequency was high, trustees had a higher incidence of compliance $\left(M_{\text {Low }}=74 \%, M_{\text {High }}=85 \%, F(1,76)=4.95, p<0.03\right)$. In addition, the frequency of monitoring also increased the amount trustees returned $\left(M_{\text {Low }}=5.57, M_{\mathrm{High}}=7.08, F(1,76)=5.78, p<0.02\right)$. Hence, Hypothesis 2 is supported. ${ }^{5}$

Trustor behavior: For each dyad, we have multiple observations in both monitored and nonmonitored rounds. For each trustor, we computed the incidence of trusting across her entire decision history to derive a separate trusting measure for monitored and non-monitored rounds. To test our hypotheses, we conducted a 2 (frequency) x 2 (anticipation) x 2 (monitoring) ANOVA with repeated measures. As we mentioned earlier, two dyads did not experience non-monitored rounds. We used data from the remaining 78 trustors to test Hypothesis 3.

As depicted in Figure 1a, trusting rates were uniformly high across the four treatment conditions. The incidence of trusting in anticipated non-monitored rounds is not significantly different from the incidence in monitored rounds $\left(M_{\text {NonMonitored }}=83 \%, M_{\text {Monitored }}=94 \%, F(1,74)=1.27, p>0.2\right)$. Anticipation of monitoring had no impact on trustor behavior. The main effect of anticipation is insignificant on both the incidence of trusting behavior $(F(1,76)=0.34, p>0.5)$ and the amount passed $(F(1,76)=2.03, p>0.15)$.

We explored heterogeneity among trustors. The right panel of Figure 1c plots the incidence of trusting in non-monitored rounds against monitored rounds. As shown, only 8 trustors (19\%) trusted less in

\footnotetext{
${ }^{4}$ All 95\% confidence intervals (CI) reported in the paper are based on the standard errors clustered at individual level.

${ }^{5}$ The main effect of anticipation is insignificant on both total incidence of compliance $(F(1,76)=0.63, p>0.4)$ and the amount returned $(F(1,76)=0.34, p>0.5)$. Although trustees behaved opportunistically in anticipated monitoring conditions, the total incidence of compliance across both monitored and non-monitored rounds did not vary across anticipation treatment conditions.
} 
non-monitored than they did in monitored rounds. ${ }^{6}$ A total of 29 of the trustors (69\%) chose to trust in all of the monitored and non-monitored rounds. The remaining 5 trustors (12\%) trusted more in non-monitored rounds.

These results appear to suggest that the strong-form of trust inference in Hypothesis 3a is supported for a large proportion (69\%) of the trustors. For the $19 \%$ of the trustors who might be aware of the potential breach of trust by the trustees, these trustors did not make a sufficient adjustment to mitigate this risk. They passed positive amount in 63\% of the non-monitored rounds. Their behavior is consistent with the weak-form of trust inference (Hypothesis 3b).

We found no support for Hypothesis 4. The frequency of monitoring overall did not significantly affect the decision to trust $\left(M_{\text {Low }}=88 \%, M_{\text {High }}=89 \%, F(1,76)=0.01, p>0.9\right)$, or the amount that they passed $\left(M_{\text {Low }}=3.22, M_{\text {High }}=3.75, F(1,76)=2.76, p=0.10\right)$.

To provide a better sense of trustors' investment outcomes, in Figure 2a we present a scatter plot of the amount trustees returned against the amount trustors passed for each of the four treatment conditions. In each plot, the 45 degree line represents the case where the amount passed equals the amount returned. The top panel plots show data from the anticipated treatment conditions and the bottom panel plots show data from the unanticipated treatment conditions. We use solid dots to represent non-monitored rounds and hollow dots to represent monitored rounds. As shown in the top panel plots, many solid dots are below the 45 degree line, indicating that trustors in the anticipated non-monitored rounds received a negative profit. In the bottom panel plots, the same solid dots are generally above the 45 degree line, suggesting that trustors enjoyed a positive profit in unanticipated non-monitored rounds. Note that hollow dots are frequently above the 45 degree line in both the top and bottom panel plots, indicating that trustors often enjoyed a positive return in monitored rounds, regardless of whether or not monitoring was anticipated.

In Figure 2b, we present the average amount passed and returned conditional on that trustors passed a positive amount. The figure shows that the average amount returned was always much higher than the average amount passed in all except the two conditions involving anticipated non-monitored rounds. In anticipated non-monitoring rounds, the average amount trustees returned was slightly lower than the average amount trustors passed. Figure 2c demonstrates this empirical regularity by taking the difference between the amount trustors passed and the amount trustees returned. As shown, trustees returned significantly less in anticipated non-monitored rounds. Note that trusting in anticipated non-monitored rounds did not yield a positive profit ( $M_{\text {Low }}=-0.11,95 \%$ CI: $[-1.45,1.22] ; M_{\text {High }}=-0.31,95 \%$ CI: $\left.[-1.99,1.37]\right)$.

\footnotetext{
${ }^{6}$ Note that only 2 out of these 8 trustors made significantly more trusting choices in monitored than non-monitored rounds (two-tailed proportion test: $p<0.05$ ).
} 
Insert Figure 2 about here

\section{Regression Analyses}

We conducted a set of logistic regression analyses to explore whether trustee behavior in a monitored round influenced trustor behavior in the subsequent non-monitored round. If trustors drew positive inference of trustworthiness based on observed compliance, we would expect trustees' compliance in the most recent anticipated monitored round to influence trustors' trusting in the following anticipated non-monitored round. We limited our data for this regression to non-monitored rounds. We used trustors' trusting decision as the dependent variable. The independent variables are the round number and whether the trustee complied in the most recent monitored round. We report the results from this regression in Table 1 . We found a significant, positive effect for trustees' compliance in monitored rounds. This is true both when monitoring was unanticipated (in this case, it was diagnostic of what trustees would do in non-monitored rounds), and when monitoring was anticipated (in this case, it was less diagnostic of what trustees would do in non-monitored rounds). These findings are consistent with the trust inference hypothesis that postulates that trusting decisions are influenced by what trustors observed in monitored rounds.

Insert Table 1 about here

\section{Discussion}

Monitoring significantly influenced trustee and trustor behavior. Trustees were more compliant when they anticipated that their counterparts would observe their behavior. When trustees anticipated that their counterparts would not observe their behavior, they were opportunistic and far less compliant. As a consequence, the expected rate of return in anticipated non-monitored rounds was not statistically different from zero. Though both trustors and trustees were drawn from the same population, the majority of trustors failed to appreciate how strategically their counterparts would behave when monitoring was anticipated. Instead, trustors behaved similarly in all anticipated rounds, regardless of whether these rounds were monitored or not. Our findings suggest that trustors relied on the behavior they observed and failed to appreciate how strategic their counterparts would be.

The frequency of monitoring only modestly influenced trustees and trustors' behavior. It is possible that a single violation would so significantly harm the relationship that even infrequent (40\%) monitoring was sufficient to promote trust and compliance. 
Our findings identify an important puzzle. Trustees reacted strategically to anticipated monitoring, but trustors were less sensitive to anticipated monitoring. One possible account for this asymmetric response is a perspective taking failure. Trustors may have failed to take their counterparts' perspective. A second account for the divergent behavior we observed involves reciprocity. Although trusting in non-monitored rounds entails risk, it may boost cooperation by triggering reciprocity from the trustee in future, nonmonitored rounds. That is, trustors may avoid passing zero amounts in non-monitored rounds, because they fear sending a signal of low trust that might harm future cooperation. ${ }^{7}$ We designed two follow-up studies that encouraged trustors to engage in perspective taking to investigate the underlying mechanism of trustors' decisions.

\section{STUDY 2: PERSPECTIVE TAKING}

In Study 1, we found that trustors were less responsive to anticipated monitoring than trustees were, and we found that trustors often earned negative profits when participants anticipated that they would not be monitored. In this study, we investigate findings. Specifically, we consider whether or not a failure in perspective taking could account for the asymmetry in trustor and trustee behavior. In this study, in addition to making decisions, we asked trustors to predict trustees' behavior, and we rewarded them for accuracy. With prediction data, we can distinguish between failed perspective taking, trustors misperceive how trustees will behave, and strategic cooperation, trustors pass to ensure future cooperation. We also explore how guiding trustors to focus on what trustees are likely to do might diminish the asymmetry between trustor and trustee behavior in anticipated non-monitored rounds.

\section{Method}

Participants. We recruited 102 participants from a large public university in Singapore. We offered participants a 5 Singapore Dollar payment (about \$4 US) show-up fee for a one-hour laboratory study plus the chance to earn additional money. We seated participants at computer cubicles, and participants could only communicate via computer. All of the experimental instructions were presented via computer and an experimenter read the instructions aloud in front of the participants. To ensure that the participants fully understood the instructions, we administered a comprehension check before participants could proceed with the experiment. Any participants who failed the comprehension check three times were dismissed together with their counterpart. In each session, the group size ranged from 22 to 28.

Design. Upon arrival in the behavioral lab, we randomly assigned each participant to a role (odd or even) and to one of two experimental conditions: control and perspective taking. In the control condition,

\footnotetext{
${ }^{7}$ We thank an anonymous reviewer for suggesting this alternative explanation.
} 
participants played a repeated trust game similar to the repeated trust game participants played in the $40 \%$ anticipated monitoring condition in Study 1. In Study 2, however, we simplified the game so that the participants made only binary choices. Specifically, rather than allowing odd players to pass different amounts of points, odd players chose to either pass their entire initial endowment of \$6 or keep all \$6. If odd players passed the $\$ 6$, the amount tripled to $\$ 18$, and even players chose to either split the $\$ 18$ evenly (\$9 for odd, \$9 for even) or keep all of the money for themselves (\$0 for odd, \$18 for even). We believe that by making the players' decisions binary, we increased comprehension without losing the key dynamics of the game.

In Study 2, we asked both odd and even players to make decisions for each round. That is, we asked even players to make a contingent decision to either split or keep the \$18 before they learned whether or not their odd player counterparts had passed them the \$6. This commonly-used "strategy method" enables us to learn even player intentions, irrespective of odd player decisions within a particular round. At the end of the experiment, we selected one of the rounds at random and we paid participants based upon the outcome of that round.

In the perspective taking condition, participants played the same version of the repeated trust game as the control condition, but we added a series of questions for the odd players. Before making their decision in each round, we asked odd players the following questions:

If you were the EVEN player in this experiment, what would you have done in this round?

What is your guess of the EVEN player's choice? (A correct guess will earn you \$0.50)

At the end of each monitored round, odd players learned what their counterparts chose. Choices of the even players in non-monitored rounds were revealed to odd players only at the end of the entire experiment.

Experimental Procedure. After each round, even players learned what the odd players did. As in Study 1 , there was an independent $40 \%$ chance that each round would be a feedback round. Both players learned whether or not the upcoming round would be a feedback round. If the round was a feedback round, odd players learned what even players chose at the end of that round. If the round was a no feedback round, odd players did not learn what even players chose until the end of the experiment. Participants remained in the same role, matched with the same partner throughout the entire experiment. As in Study 1, we used a stochastic ending. Every participant played a minimum of 14 rounds. After the $14^{\text {th }}$ round, there was an $85 \%$ chance of proceeding to round 15 , and if there was a $15^{\text {th }}$ round, there was an $85 \%$ chance of proceeding to the next round, and so on. Across both conditions, we asked odd players immediately after they made their decision, “How much do you trust your counterpart?” (1: “Not at all” to 7: “Completely”). 
At the end of the study, we collected attitudinal measures to investigate participants' perceptions of the monitoring system. After completing these measures, participants saw their entire decision history and learned which round would determine their bonus payment. In the perspective taking condition, we paid odd players an additional $\$ 0.50$ for every correct forecast they made.

\section{Results}

Of the 102 participants who came to the laboratory, 3 dyads were unable to complete the study because one of the partners in the dyad failed the comprehension check three times. We were also unable to collect data in one session because the computer program crashed shortly after the game began. As a consequence, we report results from 84 participants. A total of 18 dyads in the control condition and 24 dyads in the perspective taking condition completed the study. On average, participants completed 19.86 rounds of decisions (beyond 14, the total number of rounds each dyad completed was stochastic). We report summary statistics followed by a set of regression results.

We report passing and returning decisions by condition, and type of round in Figure 3a. Trustors trusted in $64 \%$ of the rounds in the control condition, $63 \%$ of the rounds in the perspective taking condition. Trustees complied in $47 \%$ of the rounds in the control condition, and $48 \%$ of the rounds in the perspective taking condition. On average, the incidence of compliance was lower than the incidence of trusting in both conditions. Also, we found no difference in players' behavior between the control condition and the perspective taking condition (when we asked trustors to predict trustees’ behavior).

Insert Figure 3 about here

As in Study 1, trustees made strategic decisions in response to monitoring. Trustees were far more likely to return money in anticipated monitored rounds than they were in anticipated non-monitored rounds: in the control condition: $M_{\text {Monitored }}=82 \%, M_{\text {NonMonitored }}=23 \%, F(1,40)=51.29, p<0.001$, and in the perspective taking condition: $M_{\text {Monitored }}=86 \%, M_{\text {NonMonitored }}=23 \%, F(1,40)=65.26, p<0.001^{8}$. In this study, trustors decided whether or not to pass $\$ 6$ to trustees, and trustees decided whether or not to return $\$ 9$ to trustors. Therefore, the trustors' decision to trust pays as long as the trustee counterparts return $\$ 9$ at least

\footnotetext{
${ }^{8}$ Since for each player, we have multiple observations in both monitored and non-monitored rounds, we computed the incidence of compliance (trusting) for each trustee (trustor) in monitored and non-monitored rounds across the entire decision history. With these data, we constructed separate compliance (trusting) measures for monitored and nonmonitored rounds. Our statistical tests were based on a 2 (control vs. perspective taking) x 2 (monitoring: monitored vs. non-monitored) ANOVA with repeated measures. Monitoring is the within-subject factor.
} 
$66.7 \%$ of the time. Interestingly, the percentage of rounds that trustees returned money fell below $66.7 \%$ in non-monitored rounds in both conditions.

Trustors were responsive to monitoring, but significantly less so. In the control condition: $M_{\text {Monitored }}=$ $75 \%, M_{\text {NonMonitored }}=57 \%, F(1,40)=10.09, p<0.01$; in the perspective taking condition: $M_{\text {Monitored }}=77 \%$, $M_{\text {NonMonitored }}=54 \%, F(1,40)=9.1, p<0.01$. We calculated trustors' average earnings conditional on passing across different conditions. As depicted in Figure 3b, although trustors made positive profits in monitored rounds, their average profit in non-monitored rounds was -\$3.14 (95\% CI: [-5.6, -0.65]) in the control condition and $-\$ 3.44$ (95\% CI: $[-5,-1.8]$ ) in the perspective taking condition. Put differently, for every \$6 passed, trustors received about $\$ 3$ in return from trustees. These results clearly demonstrate that trust was exploited when monitoring was absent and anticipated.

Perspective Taking. We next examine trustors' beliefs about what trustees would choose in the perspective taking condition. Trustors could make one of two types of forecasting errors: an optimistic error, expecting trustees to return money when trustees chose to keep it, or a pessimistic error, expecting trustees to keep the money when trustees chose to return it.

We identify two patterns in trustors' forecast data. First, Trustors were significantly more likely to commit errors in forecasting their counterparts' behavior in non-monitored rounds (45\%) than they were in monitored rounds $(17 \%)(F(1,23)=11.07, p<0.01)$. In non-monitored rounds, trustors' forecasts were only slightly better than chance $(z=1.7, p=0.08)$. Second, revealing a failure of perspective taking in nonmonitored rounds, trustors were far more likely to make optimistic errors (83\%) than pessimistic errors (17\%) $(z=7.24, p<0.001)$. In monitored rounds, trustors were slightly, but not significantly more likely to make pessimistic errors (63\%) than optimistic errors (37\%) $(z=1.46, p=0.2)$. Trustors' forecasts were highly correlated with their passing decisions in both non-monitored (Pearson's $\rho=.61$ ) and monitored (Pearson's $\rho$ $=.69$ ) rounds. These data support the account that failed perspective taking and an over-reliance on observable behavior causes trustors to misplace their trust in non-monitored rounds. We depict trustors' forecast errors in Figure 4.

Insert Figure 4 about here

Our perspective taking intervention did not significantly attenuated misplaced trust in anticipated, non-monitored rounds. In non-monitored rounds, trustors passed similar amounts in the control condition and the perspective taking condition, $\left(M_{\text {Control }}=57 \%, M_{\text {Perspective }}=54 \%, F(1,40)=0.03, N S\right)$.

In Hypothesis 3, we postulate that trustors will overestimate the correlation between the trustees' choice in the prior monitored round and the subsequent non-monitored round. In our analyses, we focus on the rounds in which the prior round is a monitored round and the subsequent round is a non-monitored round. 
In Figure 5, we present the percentage of trusting and trustworthy behavior in a subsequent non-monitored round, conditional on trustees' compliant behavior in a prior monitored round. As shown, conditional on trustees' compliant behavior in a prior monitored round, trustors chose to trust trustees more than half of the time in the subsequent non-monitored round (73\% in the control condition, $60 \%$ in the perspective taking condition), whereas trustees actual decisions were far less correlated with their prior choice and exhibited a lower incidence of compliance (26\% in the control condition, $21 \%$ in the perspective taking condition). These results suggest that trustors incorrectly inferred that trustees' who were compliant in monitored rounds would be compliant in non-monitored rounds.

Insert Figure 5 about here

Trust Level. Trustors' passing decisions are highly correlated with trust ratings across both conditions (Pearson's $\rho>$.48). In the control condition, trustors reported the same level of trust in monitored and non-monitored rounds $\left(M_{\text {Monitored }}=4.44, M_{\text {NonMonitored }}=4.4, F(1,40)=0.001, N S\right)$. In the perspective taking condition, however, trustors reported that they trusted their trustees somewhat more in monitored rounds than they did in non-monitored rounds $\left(M_{\text {Monitored }}=4.53, M_{\text {NonMonitored }}=3.83, F(1,40)=4.25, p<\right.$ $0.06)$.

\section{Regression Analyses}

We performed a series of regression analyses to further test our hypothesis. We clustered standard errors at the individual level.

Response to Monitoring. In the first two columns of Table 2, we report results from logistic regression analyses that predict passing/returning decisions for trustors and trustees ( 1 = passing/returning, 0 = no-passing/no-returning). For independent variables we included role ( $1=$ trustee, $0=$ trustor $)$, whether or not a round is a monitored round ( 1 = monitored round, $0=$ non-monitored round), and the interaction between the two. The interaction term is positive and significant across both conditions, demonstrating that trustees were more responsive to monitoring than trustors were. The negative main effect for role reflects that, on average, trustees were less likely to return than trustors were to pass.

Insert Table 2 about here

Trustors' Reliance on Recent Observations. We conducted a regression to examine how the trustee behavior that trustors last observed influenced their decision to pass in the subsequent non-monitored round. 
In Table 3, we report results from a logistic regression using trustors' choice as the dependent variable. The focal independent variable is trustees' choice in the most recent monitored round. Across conditions, we found a significant, positive effect of the trustees' choice in the prior monitored round. That is, the decisions trustors made in non-monitored rounds are influenced by what they last observed. In the perspective taking condition, the coefficient on round is negative, suggesting that trustors became less trusting over time.

Insert Table 3 about here

We conducted a second logistic regression model to explore trustors' beliefs. In this model, we examined the extent to which a trustee's decision to return money in a prior monitored round predicts the trustors' forecast in a non-monitored round. We coded the dependent variable, trustors' forecast, as a 1 if they made an optimistic error and a 0 otherwise. As the independent variable, we included whether or not the trustees had returned money in the prior monitored round ( 1 if they did, 0 if they did not). We found that the two variables are highly related $(\beta=3.49, \mathrm{z}=3.14, \mathrm{p}<0.01)$. That is, trustee decisions in the most recent monitored round significantly influenced trustors' beliefs in non-monitored rounds.

We next conducted a linear regression predicting trust ratings. We report these results in Table 4 in the first two columns. These findings reflect a very similar pattern to what we observed in Table 3, modeling trustors' passing decisions. Most notably, the most recently observed trustee decision influenced trustors' trusting beliefs. We also found a small positive effect for round in the control condition, suggesting that trustors' trusting beliefs increased over time in the control condition.

Insert Table 4 about here

\section{Discussion}

In Study 2, we extended our investigation of monitoring and trust. In this study, we focused on anticipated monitoring and the failure of trustors to appreciate how strategically trustees behave. When trustees anticipated that they would be monitored, they were highly compliant. When trustees anticipated that they would not be monitored, however, they were far less compliant. Trustors, however, failed to anticipate this, and as a consequence earned negative returns from investment in the non-monitored rounds.

In this study, we also included a perspective taking condition. In this condition, we asked trustors to forecast trustee behavior, and we incentivized accurate forecasts. We found that trustors systematically mispredicted trustee behavior in anticipated, non-monitored rounds. These mispredictions were not random. Rather, trustors expected trustees to be trustworthy far more often than they actually were. In this study, we 
also measured attitudinal trust. We found that attitudinal trust was highly correlated with trustor decisions to pass. We also found that trustors maintained high trust in anticipated non-monitored rounds.

Across both the perspective taking and the control conditions, trustors were heavily influenced by the trustee behavior they observed. When trustees passed in anticipated monitored rounds, trustors expected trustees to be significantly more likely to pass in subsequent anticipated, non-monitored rounds. That is, prior compliance in monitored rounds increased both attitudinal trust and the likelihood that trustors would pass. These findings are inconsistent with Strickland (1958)'s prediction, but support our weak trust inference hypothesis.

Overall, the experience of forecasting counterparts' behavior made trustors slightly less trusting in non-monitored rounds. This effect, however, was small. It is possible that with greater experience trustors would develop more accurate perceptions. We consider this proposition in our next study, where we expose trustors to more information.

Taken together, our findings documented a surprising perspective taking failure. Though trustors and trustees were drawn from the same sample population, the strategic perspectives they adopted were highly disparate. An incentivized perspective taking condition revealed—rather than mitigated—this effect.

\section{STUDY 3: LEARNING FROM OTHERS’ EXPERIENCE}

In Study 3, we extend our investigation of anticipated monitoring, and we used methods similar to those we used in Study 2. In this study, participants played the same binary-choice repeated trust game as they did in Study 2. To moderate the perspective taking failure we documented in Studies 1 and 2, we included a condition in which trustors observed behaviors in other dyads. Specifically, trustors could observe and learned how the trustees in other dyads responded to monitoring.

By observing trustee behavior in in other dyads, trustors witnessed strategic trustee behavior. These observations should mitigate the perspective taking failure-trustors expect trustees to be compliant in anticipated non-monitored rounds even though trustees behave opportunistically. However, recent work suggests that learning from the experiences of others is limited. The same information is weighted more heavily if it arises from direct experience rather than from observation (Simonsohn, Karlsson, Loewenstein, and Ariely 2008; Haselhuhn, Pope, Schweitzer, and Fishman 2012). It is possible that trustors may discount the information they glean from observing others and instead rely heavily on their own direct, positive experience - even when these experiences come from a biased set of monitored rounds. If participants fail to lean from others’ experiences, we would observe persistent over-trusting in non-monitored rounds. 


\section{Method}

Participants. As in Study 2, we recruited student participants from a university in Singapore to participate in a one-hour laboratory study in exchange for a 5 Singapore Dollar (about \$4 US) show-up fee and the opportunity to earn additional money. We recruited 108 participants and after explaining the procedures, we administered a short comprehension quiz. Any participant who failed the quiz three times was dismissed together with their counterpart.

Design. As in Study 2, we used the binary version of the trust game with $40 \%$ Anticipated Monitoring. Odd players could either keep \$6 or pass it to their even player counterparts. If they passed the $\$ 6$, the amount triples and their counterparts had \$18 to either split evenly or keep all for themselves. As in Study 2, we used the strategy method and asked even players to make their decision before knowing whether or not their odd player counterparts had passed their initial endowment in each round.

In this study, within each session, we assigned half of the participants to the control condition, and half to the observe condition. Odd players in the observe condition played the same repeated trust game with a partner as those in the control condition, but these odd players were also able to observe behavior of the dyads in the control condition. Specifically, in the observe condition, odd players saw a summary table after each round that depicted the odd and even player decisions of dyads in the control condition (see Figure 6 for a screenshot). The summary table also indicated whether or not the round for dyads in the control condition was an anticipated monitored round or an anticipated non-monitored round. Participants in the control condition did not know that their behavior would be observed by other participants, and we did not inform even players in the observe condition that their counterparts were observing the decisions of other groups.

Insert Figure 6 about here

Experimental Procedure. As in Study 2, there was an independent $40 \%$ chance that any round would be a feedback round. Participants remained in the same role with the same partner throughout the entire experiment. Similar to the stochastic ending rule we used in Study 2, everyone played 14 rounds, and after round 14, for every subsequent round, there was an $85 \%$ chance of proceeding to the next round. For each round, immediately after trustors made their decision, we asked the trustors "How much do you trust your counterpart?” (1: “Not at all” to 7: “Completely”).

In the observe condition, immediately after odd players indicated how much they trusted their counterparts, odd players saw a summary table of the full set of decisions and whether or not a round was a monitored round for every dyad in the control condition within their session. At the end of the study, we asked post-experiment questions, revealed the entire history of their own game, randomly selected one of the rounds, and paid participants based upon their outcome for that round. 


\section{Results}

One participant failed the comprehension quiz three times, and we dismissed that participant and their counterpart. We report results from the remaining 106 participants; 28 dyads made decisions in the control condition and 25 dyads made decisions in the observe condition. On average, the participants completed 20.8 rounds. The number of participants per session ranged from 22 to 28 . We report summary statistics followed by a set of regression analyses.

Trustors trusted in $56 \%$ of the rounds in the control condition, and in $60 \%$ of rounds in the observe condition. Trustees complied in 54\% of the rounds in the control condition, and in 50\% of rounds in the observe condition. On average, the incidence of compliance is lower than the incidence of trusting in both conditions.

As in Studies 1 and 2, trustees behaved very strategically in response to anticipated monitoring. Trustees passed significantly more often in monitored rounds than they did in non-monitored rounds (in the control condition: $M_{\text {Monitored }}=85 \%, M_{\text {NonMonitored }}=34 \%, F(1,51)=77.67, p<0.001$; in the observing condition: $\left.M_{\text {Monitored }}=85 \%, M_{\text {NonMonitored }}=26 \%, F(1,51)=82.51, p<0.001\right)$. Similar to Study 2, in nonmonitored rounds, the incidence of compliance fell below of $66.7 \%$ rate, the break-even point, which indicates that investment yields negative expected profit when monitoring is absent. In the non-monitored rounds, the average profit from investment is negative: $-\$ 2.19$ (95\% CI: $-4.3,-0.03])$ in the control condition and $-\$ 2.64$ (95\% CI: $[-4.9,-0.34])$ in the observe condition. These results again demonstrate that trust was misplaced in non-monitored rounds.

Trustors were also responsive to whether or not the round was monitored. Trustors were more likely to pass in monitored rounds than they were in non-monitored rounds (in the control condition: $M_{\text {Monitored }}=$ $68 \%, M_{\text {NonMonitored }}=47 \%, F(1,51)=9.09, p<0.01$; in the observing condition: $M_{\text {Monitored }}=77 \%, M_{\text {NonMonitored }}=$ $49 \%, F(1,51)=22.46, p<0.001)$. And trustors in the observing condition passed just as often in the nonmonitored rounds as they did in the control condition: $M_{\text {Control }}=47 \%$ vs. $M_{\text {Observing }}=49 \%, F(1,51)=0.11, p>$ 0.9. Trustors in the observing condition passed slightly more often in the monitored rounds than they did in the control condition, but the difference is not significant: $M_{\text {Control }}=68 \%$ vs. $M_{\text {Observing }}=77 \%, F(1,51)=1.98$, $p>0.16)$.

Response to Monitoring. Trustors were less responsive to whether or not a round was a monitored round than trustees, and in non-monitored rounds, trustors passed significantly more than they should have. In Table 2 in the last two columns, we report results from logistic regressions that analyzes passing decisions. We modeled trustor and trustee passing/returning decisions ( 1 for passing/returning, and 0 otherwise) as a function of Role ( 1 = trustee, 0 = trustor), Monitoring ( 1 for a monitored round and 0 for non-monitoring), and the interaction between Role and Monitoring. The interaction is positive and significant in both 
conditions, indicating that trustees are more sensitive to monitoring than trustors. The main effect for role type in the observing condition is negative, indicating that trustees on average were less likely to return money than trustors were to pass.

In Table 3 in the last two columns, we report results from logistic regression models of trustors' decisions to pass in non-monitored rounds. Across conditions, we found that trustors were more likely to pass in non-monitored rounds when their trustee counterparts had returned money in the prior monitored round. We also found no effects for round. Passing behavior remained fairly constant throughout the experiment.

Consistent with Study 2, we found that trustors overestimated the correlation between trustees' choices in monitored and non-monitored rounds. Conditional on trustees' compliant behavior in prior monitored round, trustors were very likely to trust their counterparts (61\% in the control condition, $66 \%$ in the observing condition), even though trustees actual behavior was not closely related to their prior choice, reflected by a much lower returning frequency (37\% in the control condition, $38 \%$ in the observing condition). These results again reveal that trustees' prior choices in monitored rounds had a larger influence on trustors' decisions than on their own decisions in subsequent non-monitored rounds.

As in Study 2, we also explored trust ratings. Trust ratings were highly correlated with trustors' passing decisions (Pearson's $\rho>$.64). In Table 4, we report regression models of trust ratings in nonmonitored rounds. As in Study 2, these trust ratings were influenced by whether or not trustees had returned money in the prior monitored round. In the control condition, we observed a positive effect for round, indicating that trust levels increased over time in the control condition.

\section{Discussion}

In this study, we extend our investigation to explore how learning from others' experiences might improve perspective taking. In our study, trustor participants in the observe condition learned about the strategic behavior of trustees in other dyads. Their personal experience, however, was limited; they only observed their own counterparts' behavior in anticipated monitored rounds. Interestingly, it was trustors' personal experience that mattered most. Trustors in both our control and observe conditions were heavily influenced by the trustee behavior they observed in anticipated monitored rounds, and consequently very trusting in non-monitored rounds. As before, we find a consistent pattern: Trustees behaved strategically, exhibiting compliant behavior when they knew they would be monitored and exploiting trust when they knew they would not be monitored. And trustors, failing to anticipate this strategic behavior, placed too much trust in their counterparts in anticipated non-monitored rounds. 


\section{ANALYSES OF ATTITUDINAL DATA}

In Studies 2 and 3, immediately after participants completed making decisions in the repeated trust game, but before they saw the entire history, we asked participants a series of post-experiment questions to investigate three questions: how much participants trusted each other, how sensitive their decisions were to the monitoring system, and what they thought of the monitoring system.

Trust. At the end of the experiment, we asked trustors the following question, "Knowing what you know now, how much do you trust your counterpart?” (1: Not at all, 7: Completely). Across both studies, we found no significant differences in post experiment trust levels between the control and treatment conditions (In Study 2: $M_{\text {Control(PT) }}=4.78, M_{\text {Perspective }}=4.17, t(40)=1.1, N S$; In Study 3: $M_{\text {Control(OB) }}=4.15, M_{\text {Observing }}=3.52$, $t(51)=1.13, N S)$. Overall, these findings suggest that trust was not eroded by perspective taking or by observing others' strategic behavior.

Sensitivity to Monitoring. We asked both trustors and trustees to what extent "I made different decisions depending upon whether or not the round was a Feedback or No Feedback round.” (1: Strongly disagree, 7: Strong agree). Consistent with the behavior we observed in the game, across conditions trustees reported that their behavior was more heavily influenced by whether or not they anticipated feedback than trustors did. We report these results in Table 5.

Perceptions of Monitoring. We also asked participants to what extent they agreed with the following statements: "Overall, I would have preferred if more of the rounds were Feedback rounds.", "I strongly disliked the Feedback rounds.", and "It would have been better if all of the rounds were No Feedback rounds." We formed a composite measure by averaging these three evaluation measures (Cronbach's $\alpha=$ 0.79). As we expected, trustors liked feedback rounds more than trustees did, and trustees reported that they would have earned more money had there been fewer feedback rounds. We report these results in Table 5.

Insert Table 5 about here

From these post experiment questions, we find that trustees correctly recognized that they were more strategic in their response to monitoring than trustors were. We also find that trustees liked the non-monitored rounds and disliked monitored rounds more than trustors. That is, trustees behaved strategically and recognized that they could earn greater surplus by exploiting their counterparts. 


\section{GENERAL DISCUSSION}

Our work investigates how monitoring influences behavior. We report results from a series of repeated trust game experiments and describe how monitoring systems influence the behavior of both those who were monitored and those who monitored and observed their counterparts' behavior. Our findings reveal that trustees and trustors respond to monitoring in an asymmetric way. Trustees were significantly more compliant when they anticipated monitoring and knew that their counterparts would observe their behavior. When trustees anticipated that their counterparts would not observe their behavior, however, they were opportunistic and far less compliant. Interestingly, trustors failed to anticipate this opportunistic behavior. Instead, trustors maintained high levels of trust in their counterparts, mispredicted how trustworthy their counterparts would be, and passed substantial amounts to their counterparts when they knew that their counterparts anticipated that they would not be monitored.

Across three studies, we find that trustors relied on the behavior they observed in anticipated monitored rounds and failed to appreciate how strategically their counterparts would act. This perspective taking failure is striking because both the trustors and trustees were drawn from the same subject pool and were randomly assigned to one of the two roles in our studies. In Study 2, we investigate perspective taking. We asked trustors to forecast their counterparts' behavior and we offered trustors an incentive for accuracy. In anticipated non-monitored rounds, trustors mispredicted their counterparts' behavior. Trustors expected their counterparts to return money far more often than they actually did. Consistent with these predictions, trustors routinely passed money in anticipated non-monitored rounds and trustees exploited this trust. Interestingly, a prompt to forecast what their counterparts would do revealed rather than remedied this perspective taking failure.

In Study 3, we gave trustors information about the behavior of trustors and trustees in other dyads. Specifically, observer trustors were able to see trustees in other dyads engage in compliant behavior when they anticipated monitoring, and exploitive behavior when they anticipated that they would not be monitored. When it came to making their own decisions, however, trustors who had just seen other trustees engage in strategic behavior, relied on the non-representative behavior they observed from their own trustee, and trusted their own (similarly strategic) trustees.

In our studies, most trustors observed compliant behavior in anticipated monitored rounds. Though some scholars (e.g., Strickland 1958) have suggested that individuals will attribute monitored behavior to situational, rather than personal characteristics, participants in our studies reported high levels of trust in their counterparts after observing their compliant behavior. This trust was systematically misplaced as our participants made systematic attribution errors (Tetlock 1985; Ross 1977). Rather than accounting for the 
influence of the monitoring system on their behavior, trustors made personal attributions for the compliant behavior they observed.

The challenge of misplacing trust may be particularly important for managers. Not only do managers routinely face the challenge of trusting others, but they may also be especially ill-equipped to contend with it. Perspective taking within trust relationships is difficult in general (Weber, Malhotra, and Murnighan 2004), and high status individuals, like managers, tend to be particularly trusting (Lount and Pettit 2012). Our research demonstrates that managers should view the behavior they observe skeptically, consider changing the nature of the monitoring system they use, and recognize that what they cannot see may be far more diagnostic of trustworthiness than what they can.

By making behavior visible, monitoring allows trustors to punish uncooperative acts. Monitoring systems play a critical role in promoting cooperation, and as Nagin et al. (2002) showed in a field experiment, a reduction in monitoring can harm cooperative behavior and promote employee malfeasance. On the other hand, frequent monitoring can harm an organizational culture by communicating distrust, provoking reactance, and promoting counterproductive behavior (Cialdini 1996). Future work should explore these possible consequences to discern when and how monitoring will be most effective.

For monitoring systems to be effective, accountability and a sense of shared identity (Shapiro, Sheppard, Cheraskin 1992) may be particularly important. Characteristics of the monitoring system (e.g., peer reports, technological monitoring, and the obtrusiveness of the monitoring system in general), the organizational culture, and the nature of the task are also likely to moderate the influence of monitoring systems on behavior. Across our experiments, we demonstrate that monitoring systems change behavior in ways that our participants fail to anticipate. It is quite possible that to mitigate this perspective taking failure, the organization should incorporate richer psychological and social elements into monitoring system design. We call for future work to explore this fruitful and important area. 


\section{REFERENCES}

Association of Certified Fraud Examiners. (2012). Report to the Nations on Occupational Fraud and Abuse, http://www.acfe.com/

Aiello, J. (1993). Computer-based monitoring: Electronic surveillance and its Effects. Journal of Applied Social Psychology, 23, 499-507.

Alder, S., Noel, T., \& Ambrose, M. (2006). Clarifying the Effects of Internet Monitoring on Job Attitudes: The Mediating Role of Employee Trust, Information and Management, 43, 894-903.

American Management Association (2007), Electronic Monitoring and Surveillance Survey, http://www.amanet.org/news/177.aspx, (accessed 21 May 2010).

Andrade, E. and Ho, T. (2007) How is the Boss's Mood Today? I Want a Raise. Psychological Science, 18(8), 668-671.

Andrade, E. and Ho, T. (2009). Gaming Emotions in Social Interactions, Journal of Consumer Research, 36, 539-552.

Berg, J., Dickhaut, J. \& McCabe, K. (1995). Trust, reciprocity, and social history. Games and Economic Behavior, 10, 122-142.

Cialdini R. (1996). The triple tumor structure of organizational behavior. In Codes of Conduct, ed. D. M. Messick, A. E. Tenbrunsel, pp. 44.58. New York: Russell Sage Foundation.

Dirks, K. T., \& Ferrin, D. L. (2001). The role of trust in organizational settings. Organization Science, 12, 450-467.

Dunn, J. \& Schweitzer, M. (2005). Feeling and believing: The influence of emotion on trust. Journal of Personality and Social Psychology, 88(6), 736-748.

Enzle M. E., Anderson S. C. (1993). Surveillant intentions and intrinsic motivation. Journal of Personality and Social Psychology 64, 257-266

Epstein, S. \& O’Brien, Edward (1985). The person-situation debate in historical and current perspective. Psychological Bulletin, 93, 513-537.

Frey, B. (1993). Does monitoring increase work effort? The rivalry with trust and loyalty. Economic Inquiry, 4, 663-670.

Gambetta, D. (1988). Can we trust trust? In D. Gambetta (Ed.), Trust: Making and breaking cooperative relations, 213-237. Cambridge, MA: Basil Blackwell.

Gentner, D. \& Stevens, A. (1983). Mental Models. Hillsdale, NJ: Erlbaum.

Gilovich, T., Kruger, J., \& Savitsky, K. (1999). Everyday egocentrism and everyday interpersonal problems. In R. M. Kowalski \& M. R. Leary (Eds.), The social psychology of emotional and behavioral problems: Interfaces of social and clinical psychology. Washington, DC: American Psychological Association. 69-95. 
Goffman, E. (1959). The Presentation of Self in Everyday Life. New York: Doubleday Anchor.

Haselhuh, M., Pope, D., Schweitzer, M., Fishman, P. (2012). The Impact of Personal Experience on Behavior: Evidence from Video-Rental Fines, Management Science, 58, 52-61.

Haselhuhn, M., Schweitzer, M. Wood, A. (2010). How implicit beliefs influence trust recovery, Psychological Science, 21 (2010), pp. 645-648.

Ho, T. \& Weigelt, K. (2005). Trust Building Among Strangers. Management Science, 51, 519-530.

Kim, P. H., Dirks, K. T., Cooper, C., \& Ferrin, D. L. (2006). When more blame is better than less: The implications of internal vs. external attributions for the repair of trust after a competence- vs. integritybased violation. Organizational Behavior and Human Decision Processes, 99, 49-65.

Kim, P., Ferrin, D., Cooper, C., \& Dirks, K. (2004). Removing the shadow of suspicion: The effects of apology versus denial for repairing competence-versus integrity-based trust violations. Journal of Applied Psychology, 89, 104-118.

Kramer, R. (1999). Trust and distrust in organizations: Emerging perspectives, enduring questions. Annual Review of Psychology, 50: 569-598.

Kramer, R. \& Lewicki, R. (2010) Repairing and enhancing trust: Approaches to reducing organizational trust deficits, The Academy of Management Annals, 4, 245-277.

Kramer, R. \& Tyler, T. (1996) Trust in Organizations. Thousand Oaks, CA: Sage.

Kruglanski, A. (1970). Attributing trustworthiness in supervisor-worker relations. Journal of Experimental Social Psychology, 6, 214-232.

Leary, M. (1996). Self-Presentation: Impression Management and Interpersonal Behavior. Dubuque, IA: Brown \& Benchmark.

Lewicki, R. J., Tomlinson, E. C., \& Gillespie, N. (2006). Models of interpersonal trust development: Theoretical approaches, empirical evidence, and future directions. Journal of Management, 32: 9911022.

Lount, R. (2010). The impact of positive mood on trust in interpersonal and intergroup interactions. Journal of Personality and Social Psychology. 98, 420-433.

Lount R., Zhong C., Sivanathan N., Murnighan K.(2008). Getting off on the wrong foot: The timing of the breach and the restoration of trust. Personality and Social Psychology Bulletin. 34: 1601-1612.

Lount, R. \& Pettit, N. (2012). The social context of trust: The role of status, Organizational Behavior and Human Decision Processes, 117, 15-23.

Malhotra, D. (2004) Trust and reciprocity decisions: The differing perspectives of trustors and trusted parties, Organizational Behavior and Human Decision Processes, 94, 61-73.

Malhotra, D., \& Murnighan, J. K. (2002). The effects of formal and informal contracts on interpersonal trust. Administrative Science Quarterly, 47, 534-559. 
Mayer, R. C., Davis, J. H., \& Schoorman, F. D. (1995). An integrative model of organizational trust. Academy of Management Review, 20, 709-734.

Nagin, D.S., Rebitzer, J., Sanders, S., and Taylor, L. (2002). Monitoring, Motivation and Management: The Determinants of Opportunistic Behavior in a Field Experiment. American Economic Review 92, 850872.

Niehoff, B. P., \& Moorman, R. H. (1993). Justice as a mediator of the relationship between methods of monitoring and organizational citizenship behavior. Academy of Management Journal, 36: 527-556.

Pillutla, M., Malhotra, D., \& Murnighan, J. K. (2003). Attributions of trust and the calculus of reciprocity. Journal of Experimental Social Psychology, 39, 448-455.

Ross, L. 1977. The intuitive psychologist and his shortcomings: Distortions in the attribution process. In L. Berkowitz (Ed.), Advances in Experimental Social Psychology, 10. New York: Academic Press.

Rotter, J. B. 1971. Generalized expectancies for interpersonal trust. American Psychologist, 26, 443-452

Rotter, J. B. 1980. Interpersonal trust, trustworthiness, and gullibility. American Psychologist, 35, 1-7

Shapiro, D., B. H. Sheppard, and L. Cheraskin (1992), Business on a Handshake, Negotiation Journal, 8 (4), 365-377.

Schlenker, B. \& Leary, M. (1982). Social anxiety and self-presentation: a conceptualization and model, Psychological Bulletin. 92:641-69.

Schweitzer, M., Hershey, J., \& Bradlow, E. (2006). Promises and lies: Restoring violated trust. Organizational Behavior and Human Decision Processes, 101(1), 1-19.

Schweitzer, M. \& Ho, T. (2005). Trust but verify: Monitoring in interdependent relationships, in Experimental and Behavioral Economics (Ed. J. Morgan), 13, 87-106.

Simonsohn, U., Karlsson, N., Loewenstein G., \& Ariely, D. (2008). The tree of experience in the forest of information: Overweighing experienced relative to observed information, Games and Economic Behavior, 62, 263-286.

Senge, P. (1990). The Fifth Discipline: The Art and Practice of the Learning Organization. New York: Doubleday.

Strickland, L. (1958). Surveillance and Trust. Journal of Personality, 26, 200-215.

Tetlock, P. E. (1985). Accountability: A social check on the fundamental attribution error. Social Psychology Quarterly, 227-236.

Weber, J., Malhotra, D., \& Murnighan, J. (2004). Normal acts of irrational trust: Motivated attributions and the trust development process, Research in Organizational Behavior, 26, 75-101. 


\section{Figures}

Figure 1:

Figure 1a. Incidence of Trusting Behavior

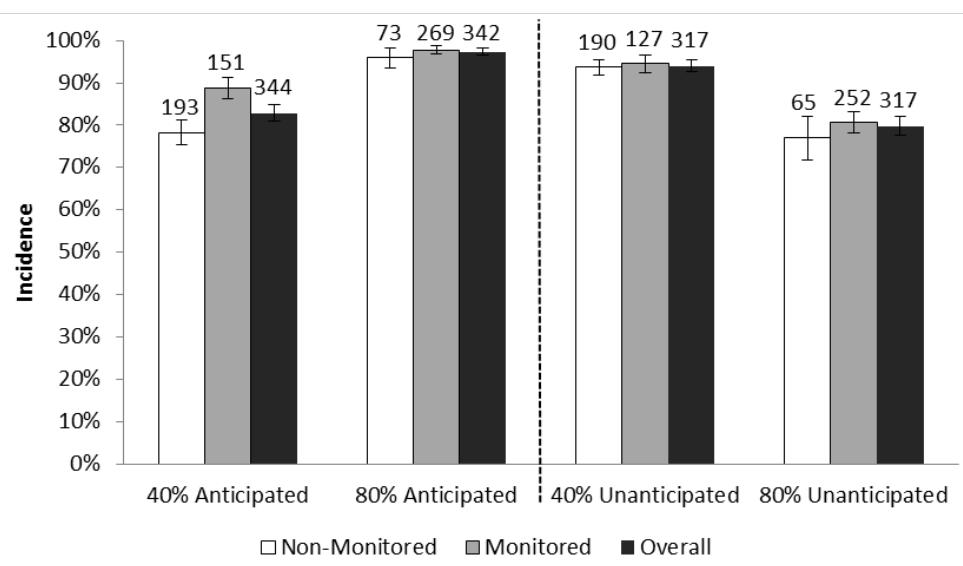

Note: Across all conditions, trustors trusted in at least $80 \%$ of the rounds. Error bars represent \pm 1 standard errors. Numbers above the bars are the number of observations.

Figure 1b. Incidence of Compliant Behavior

Conditional on Trusting (Positive Passing)

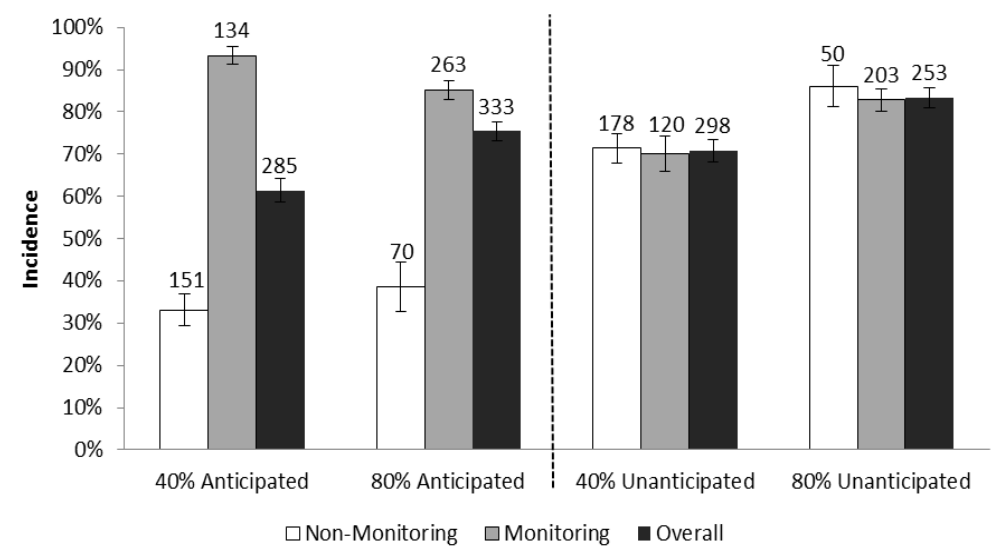

Note: Trustees were more likely to be complaint in anticipated monitored rounds, but less likely to be compliant in anticipated non-monitored rounds. Error bars represent \pm 1 standard errors. Numbers above the bars indicate the number of observations. 
Figure 1c. Individual's Incidence of Compliant and Trusting Behavior in Anticipated Monitored and Non-monitored Rounds

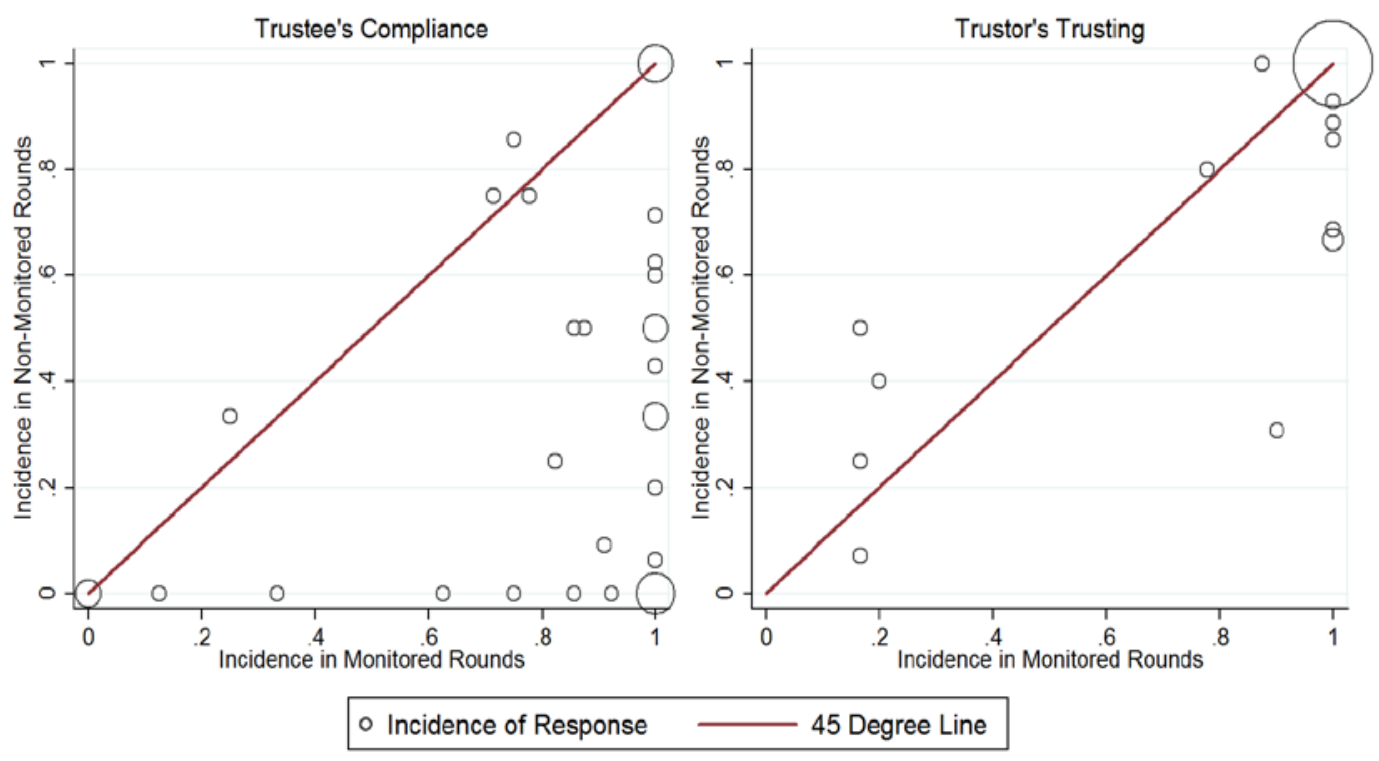

Note: The horizontal axis represents the incidence of compliance (trusting) behavior in anticipated monitored rounds. The vertical axis represents the incidence of compliance (trusting) behavior in anticipated nonmonitored rounds. If the incidence of compliance (trusting) behavior in anticipated monitored and nonmonitored rounds were equal, the data would fall along the 45 degree line. Observations below the 45 degree line represent strategic behavior. The size of the circle indicates the frequency of observations. $71 \%$ of the trustees were more compliant in monitored rounds than they were in non-monitored rounds, whereas $69 \%$ of the trustors trusted in all anticipated monitored and non-monitored rounds. 
Figure 2

Figure 2a. Scatter Plot of the Amount Returned and Amount Passed Conditional on Positive Passing
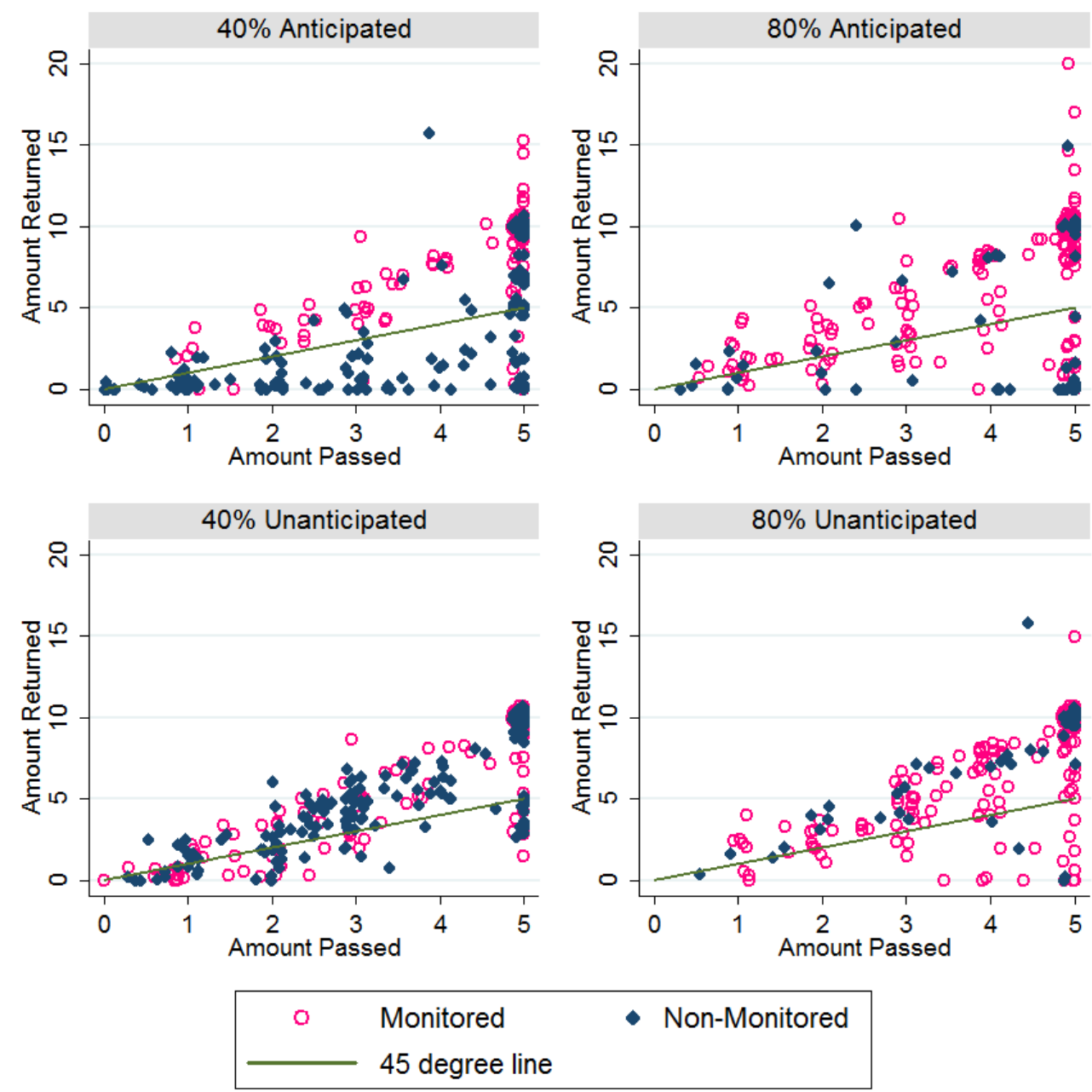

Note: The solid line represents the 45 degree line; observations along this line reflect rounds in which the amount trustors passed equaled the amount trustees returned. In anticipated non-monitored rounds (the top panel plots), large number of trustees' returned amounts in non-monitored rounds (solid dots) that were less than what they received; these observations fell below the 45 degree line, indicating that trustors received a negative profit. 
Figure 2b. The Amount Passed and Returned

Conditional on Positive Passing

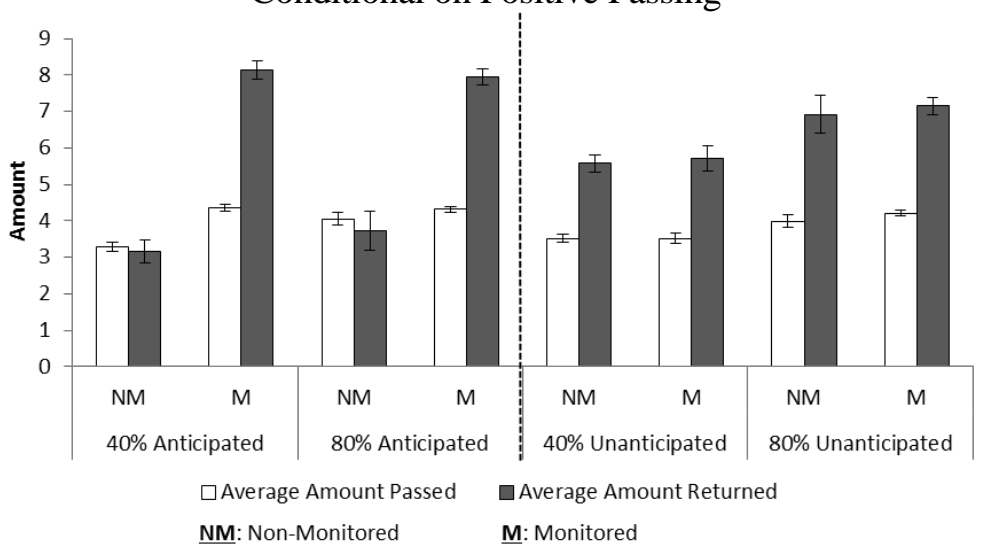

Figure 2c. The Difference between the Amount Passed and Returned Conditional on Positive Passing

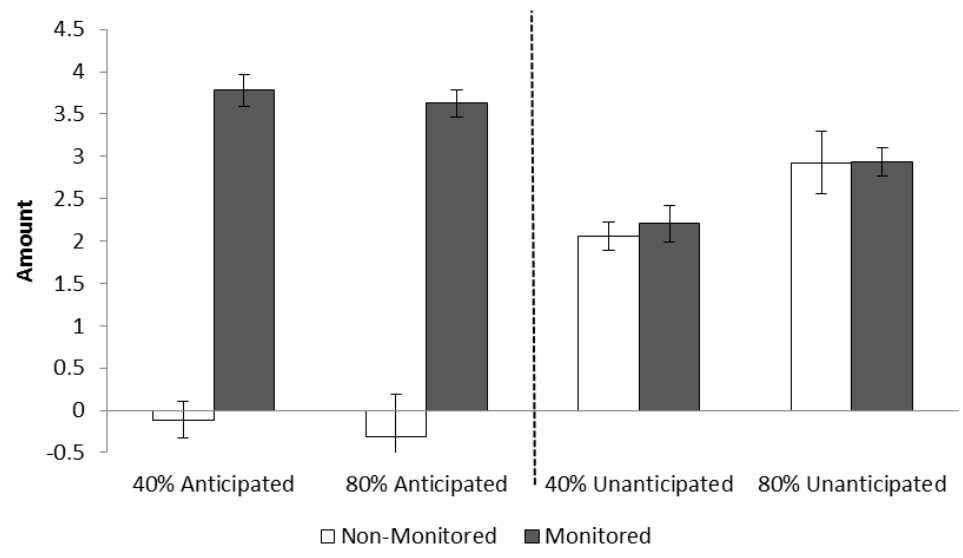

Note: Trusting yielded positive profit in all conditions except in anticipated non-monitored rounds. Error bars represent \pm 1 standard errors. 
Figure 3:

Figure 3a. Incidence of Passing and Returning by Condition and Type of Round

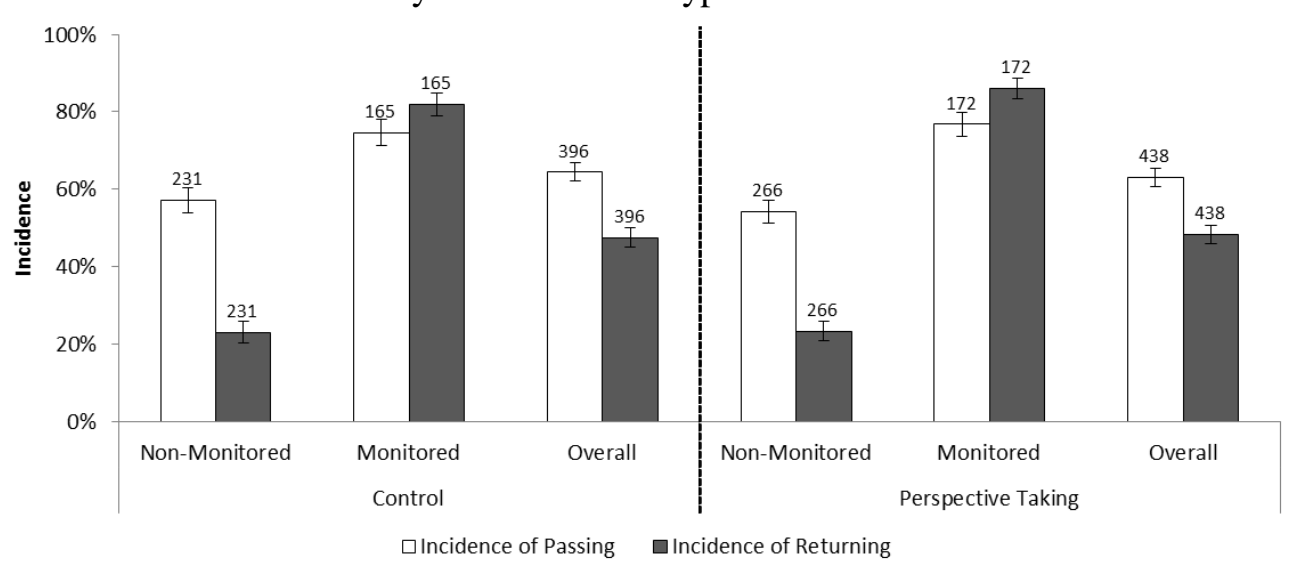

Note: Trustees were more responsive to monitoring than trustors. Error bars represent \pm 1 standard errors.

Figure 3b. Profit for Trustors Conditional on Passing

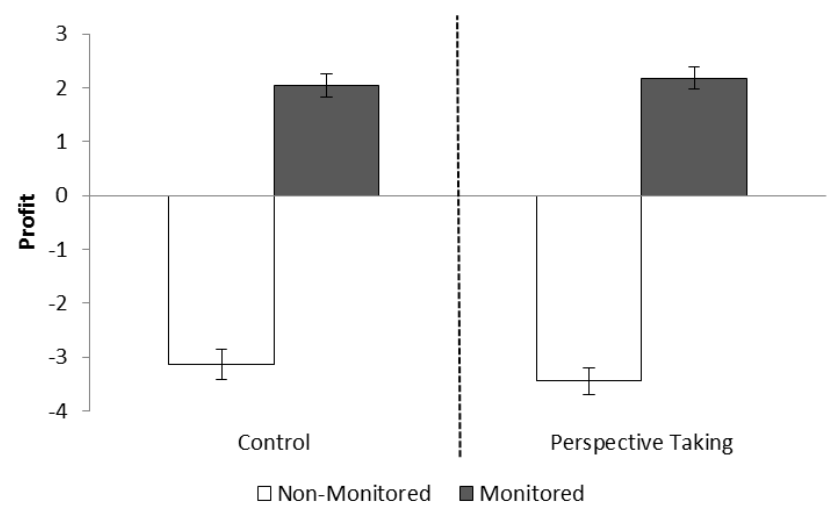

Note: Conditional on passing, the profit from investment was negative in non-monitored rounds. Error bars represent \pm 1 standard errors. 
Figure 4: Trustors’ Forecasting Error

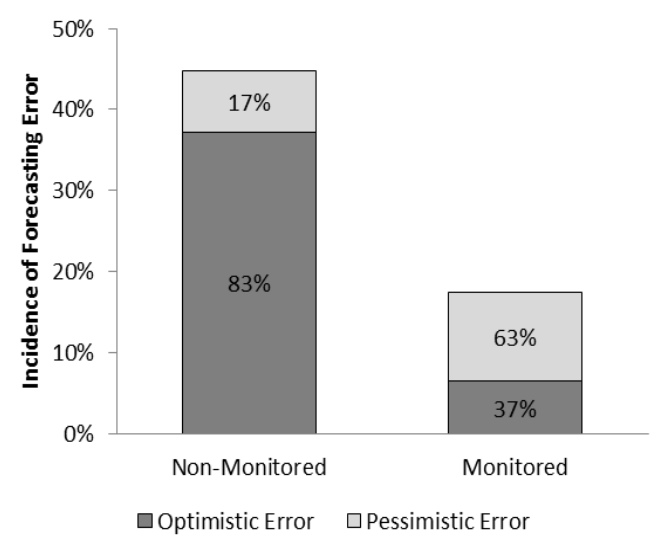

Note: Trustors made twice as many forecast errors in non-monitored rounds as they did in monitored rounds. In non-monitored rounds, the large majority (83\%) of these errors were optimistic errors.

Figure 5: Influence of Observed Compliance (Returning Behavior) in a Prior Monitored Round on Behavior in a Subsequent Non-Monitored Round

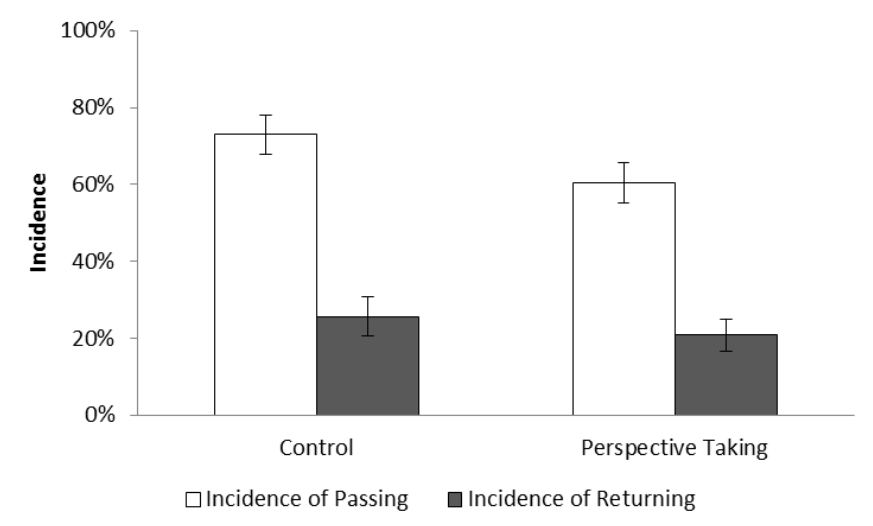

Note: When trustees were compliant in the prior, monitored round, it heavily influenced subsequent trustor behavior in the non-monitored round. Trustee behavior, however, varied substantially across monitored and non-monitored rounds. (Two-tailed proportion test: $p<0.05$ for both the conditions). Error bars represent \pm 1 standard errors. 
Figure 6: Screenshot of Trustor's Observation Table

\section{End of Round 3}

EVEN chose RETURN \$9.

\section{Observation Table}

Other matched pairs in the experiment made the following decisions in the prior rounds.

\begin{tabular}{c|c|c|c|c|c|c|c|c|} 
Round & Pair & Feedback? & $\begin{array}{c}\text { ODD } \\
\text { Chose }\end{array}$ & $\begin{array}{c}\text { EVEN } \\
\text { Chose }\end{array}$ & $\begin{array}{c}\text { Odd's } \\
\text { Payoff }\end{array}$ & $\begin{array}{c}\text { Even's } \\
\text { Payoff }\end{array}$ & $\begin{array}{c}\text { Odd's Total } \\
\text { Payoff }\end{array}$ & $\begin{array}{c}\text { Even's Total } \\
\text { Payoff }\end{array}$ \\
\hline 1 & 1 & No & PASS \$6 & RETURN \$0 & 0 & 18 & 0 & 18 \\
\hline 2 & 1 & Yes & PASS \$6 & RETURN \$9 & 9 & 9 & 9 & 27 \\
\hline 3 & 1 & No & PASS \$6 & RETURN \$0 & 0 & 18 & 9 & 45 \\
\hline 1 & 2 & No & TAKE \$6 & RETURN \$0 & 6 & 0 & 6 & 0 \\
\hline 2 & 2 & Yes & TAKE \$6 & RETURN \$9 & 6 & 0 & 12 & 9 \\
\hline 3 & 2 & Yes & PASS \$6 & RETURN \$9 & 9 & 9 & 21 & 9 \\
\hline 1 & 3 & No & PASS \$6 & RETURN \$9 & 9 & 9 & 9 & 9 \\
\hline 2 & 3 & Yes & PASS \$6 & RETURN \$0 & 0 & 18 & 9 & 27 \\
\hline 3 & 3 & No & TAKE \$6 & RETURN \$9 & 6 & 0 & 15 & 27 \\
\hline
\end{tabular}

Click on the CONTINUE button to proceed.

\section{CONTINUE}

Note: In the observe condition, right after trustors (odd player) made their decisions, the screen displayed which round was concluded - "End of Round 3", the feedback - "EVEN chose RETURN \$9", and the observation table. In this example, the trustors were able to observe other 3 pairs' behavior in the control condition. 


\section{Tables}

Table 1: Trustors’ Passing in Non-Monitored Rounds

\begin{tabular}{lc|c}
\hline \hline & $\begin{array}{c}\text { Anticipated } \\
\text { Monitoring }\end{array}$ & $\begin{array}{c}\text { Unanticipated } \\
\text { Monitoring }\end{array}$ \\
\hline Round & -0.011 & 0.041 \\
& $(0.04)$ & $(0.06)$ \\
Recent Observed Trustee's Compliance & $1.762^{* *}$ & $2.612^{* *}$ \\
& $(0.66)$ & $(0.86)$ \\
Trustor's Choice in the Prior Round & $3.690^{* * *}$ & 0.041 \\
& $(0.88)$ & $(1.27)$ \\
Constant & -2.436 & 0.766 \\
& $(1.50)$ & $(1.26)$ \\
\hline Log-Likelihood & -50.004 & -39.979 \\
\hline $\mathrm{N}$ & 208 & 194 \\
\hline \hline
\end{tabular}

Note: The dependent variable is trusting behavior in non-monitored rounds. The positive coefficients on Recent Observed Trustee's Compliance suggest that trustees' past compliance had a positive impact on trustors' subsequent choice in non-monitored round. We report standard errors in parentheses and we clustered these at the individual level. ${ }^{*} p<0.05,{ }^{* *} p<0.01,{ }^{* * *} p<0.001$.

Table 2 Passing and Returning Decisions by Role and Monitoring

\begin{tabular}{lcc|cc}
\hline \hline & \multicolumn{2}{c|}{ Study 2 } & \multicolumn{2}{c}{ Study 3 } \\
\cline { 2 - 5 } & Control & Perspective Taking & Control & Observe \\
\hline \multirow{2}{*}{ Role } & $-1.499^{*}$ & $-1.357^{* *}$ & -0.558 & $-0.983^{*}$ \\
& $(0.61)$ & $(0.50)$ & $(0.48)$ & $(0.47)$ \\
Monitoring & 0.787 & $1.028^{* * *}$ & $0.874^{* * *}$ & $1.310^{* * *}$ \\
& $(0.41)$ & $(0.22)$ & $(0.24)$ & $(0.25)$ \\
Role*Monitoring & $1.929^{* *}$ & $1.982^{* * *}$ & $1.507^{* * *}$ & $1.479^{* *}$ \\
& $(0.69)$ & $(0.48)$ & $(0.43)$ & $(0.51)$ \\
Constant & 0.288 & 0.166 & -0.106 & -0.054 \\
& $(0.38)$ & $(0.35)$ & $(0.36)$ & $(0.30)$ \\
\hline Log-Likelihood & -454.001 & -490.690 & -733.847 & -570.179 \\
\hline $\mathrm{N}$ & 792 & 876 & 1204 & 1002 \\
\hline \hline
\end{tabular}

Note: The dependent variable is passing and returning for both trustors and trustees. The positive interaction term indicates that trustees were more sensitive to the monitored rounds than trustors were. We report standard errors in parentheses and we clustered these at the individual level. ${ }^{*} p<0.05, * * p<0.01$, *** $p<0.001$. 
Table 3 Trustors’ Passing in Non-Monitored Rounds

\begin{tabular}{lcc|cc}
\hline \hline & \multicolumn{2}{c|}{ Study 2 } & \multicolumn{2}{c}{ Study 3 } \\
\cline { 2 - 5 } & Control & Perspective Taking & Control & Observe \\
\hline Round & -0.008 & $-0.076^{*}$ & 0.042 & -0.023 \\
& $(0.04)$ & $(0.04)$ & $(0.02)$ & $(0.03)$ \\
Recent Observed Trustee's Compliance & $2.198^{* * *}$ & $2.487^{*}$ & $1.715^{* *}$ & $1.203^{*}$ \\
& $(0.52)$ & $(1.08)$ & $(0.64)$ & $(0.54)$ \\
Trustor's Choice in the Prior Round & $2.163^{* * *}$ & $3.077^{* * *}$ & $3.760^{* * *}$ & $3.140^{* * *}$ \\
& $(0.53)$ & $(0.53)$ & $(0.69)$ & $(0.56)$ \\
Constant & $-2.866^{* *}$ & $-3.282^{*}$ & $-4.451^{* * *}$ & $-2.845^{* *}$ \\
& $(1.00)$ & $(1.41)$ & $(0.89)$ & $(0.88)$ \\
\hline Log-Likelihood & -101.132 & -94.844 & -116.503 & -113.980 \\
\hline $\mathrm{N}$ & 200 & 234 & 318 & 249 \\
\hline \hline
\end{tabular}

Note: The dependent variable is trusting behavior in non-monitored rounds. Trustors were more likely to pass in non-monitored rounds when they observed that their trustee counterparts complied in the most recent monitored round. We report standard errors in parentheses and we clustered these at the individual level. * $p<0.05, * * p<0.01, * * * p<0.001$.

Table 4 Trust Ratings in Non-Monitored Rounds

\begin{tabular}{lcc|cc}
\hline \hline & \multicolumn{2}{c|}{ Study 2 } & \multicolumn{2}{c}{ Study 3 } \\
\cline { 2 - 5 } & Control & Perspective Taking & Control & Observe \\
\hline \multirow{2}{*}{ Round } & $0.020^{*}$ & 0.004 & $0.012^{* *}$ & -0.002 \\
& $(0.01)$ & $(0.01)$ & $(0.00)$ & $(0.01)$ \\
Recent Observed Trustee's Compliance & $0.833^{* * *}$ & $0.958^{* * *}$ & $0.397^{*}$ & $0.420^{*}$ \\
& $(0.20)$ & $(0.23)$ & $(0.18)$ & $(0.20)$ \\
Trustor's Trust Rating in the Prior Round & $0.786^{* * *}$ & $0.638^{* * *}$ & $0.887^{* * *}$ & $0.847^{* * *}$ \\
& $(0.08)$ & $(0.11)$ & $(0.03)$ & $(0.05)$ \\
Constant & -0.093 & 0.353 & -0.124 & 0.040 \\
& $(0.25)$ & $(0.22)$ & $(0.16)$ & $(0.28)$ \\
\hline $\mathrm{R}$-squared & 0.277 & 0.304 & 0.189 & 0.052 \\
\hline $\mathrm{N}$ & 200 & 234 & 318 & 249 \\
\hline \hline
\end{tabular}

Note: The dependent variable is the trustors' trust rating in non-monitored rounds. We report standard errors in parentheses and we clustered these at the individual level. ${ }^{*} p<0.05,{ }^{* *} p<0.01,{ }^{* * *} p<0.001$. 
Table 5 Perceptions of the Monitoring System

\begin{tabular}{|c|c|c|c|c|c|c|}
\hline \multirow{2}{*}{ Variable } & \multirow{2}{*}{ Study } & \multirow{2}{*}{ Condition } & \multicolumn{2}{|c|}{ Trustor } & \multicolumn{2}{|c|}{ Trustee } \\
\hline & & & Mean & SE & Mean & SE \\
\hline \multirow{4}{*}{ Sensitivity to Monitoring } & \multirow{2}{*}{ Study 2} & Control & 4.43 & $(.44)$ & 5.71 & $(.34)^{*}$ \\
\hline & & Perspective Taking & 3.70 & $(.40)$ & 5.37 & $(.33)^{* *}$ \\
\hline & \multirow{2}{*}{ Study 3} & Control & 3.11 & (.43) & 4.73 & $(.37)^{* *}$ \\
\hline & & Observing & 4.22 & (.43) & 5.35 & $(.51)$ \\
\hline \multirow{4}{*}{ Liking of Monitored Round } & \multirow{2}{*}{ Study 2} & Control & 5.65 & $(.31)$ & 4.56 & $(.26)^{* *}$ \\
\hline & & Perspective Taking & 5.62 & $(.25)$ & 3.83 & $(.28)^{* * *}$ \\
\hline & \multirow{2}{*}{ Study 3} & Control & 5.33 & (.39) & 4.60 & $(.31)$ \\
\hline & & Observing & 5.22 & $(.33)$ & 3.57 & $(.30)^{* * *}$ \\
\hline \multirow{4}{*}{ Earn more in Non-monitoring Round } & \multirow{2}{*}{ Study 2} & Control & 2.61 & $(.27)$ & 4.32 & $(.36)^{* * *}$ \\
\hline & & Perspective Taking & 2.65 & $(.25)$ & 4.16 & $(.30)^{* * *}$ \\
\hline & \multirow{2}{*}{ Study 3} & Control & 3.23 & $(.32)$ & 3.51 & $(.29)$ \\
\hline & & Observing & 2.19 & $(.23)$ & 4.30 & $(.28)^{* * *}$ \\
\hline
\end{tabular}

Note: Compared to trustors, trustees were more sensitive to whether or not the rounds were monitored, had greater dislike for monitored rounds, and thought they could earn more in non-monitored rounds. We reported means and standard errors (SE) separated by trustors and trustees for each condition. We conducted two tailed t-test to test differences between trustors and trustees. $* p<0.05$, ** $p<0.01$, *** $p<0.001$. 